\title{
Diacylglycerol kinase $\zeta$ deficiency triggers early signs of aplastic anemia in mice
}

\section{Martín-Salgado $\mathrm{M}^{1^{*}}$, Andrada $\mathrm{E}^{1^{*}}$, Liébana $\mathrm{R}^{1}$ Mercedes López-Santalla ${ }^{2,3} \mathrm{M}$, and Merida $\mathrm{I}^{1}$}

${ }^{1}$ Dept of Immunology and Oncology, National Center of Biotechnology, Madrid, Spain

${ }^{2}$ Division of Hematopoietic Innovative Therapies, Centro de Investigaciones Energéticas, Medioambientales y Tecnológicas (CIEMAT), Centro de Investigación Biomédica en Red de Enfermedades Raras (CIBER-ER), Madrid, Spain

${ }^{3}$ Advanced Therapy Unit, Instituto de Investigación Sanitaria Fundación Jiménez Díaz (IISFJD/UAM), Madrid; Spain

*Equal contribution

Correspondent Author: Isabel Merida. Dept of Immunology and Oncology, National Center of Biotechnology, Darwin 3, 28049 Madrid, Spain. Email: imerida@cnb.csic.es. ORCID number: https://orcid.org/0000-0003-2762-6241

Keywords: (MeSH thesaurus preferred as source for choosing keywords)

Bone marrow, T helper $1 \mathrm{~T}$ cells, cytotoxic T cells, anemia, autoimmunity, diacylglycerol

Running title: DGK $\zeta$ limits T cell activation in the bone marrow

Word counts: Abstract:212; Text: 3769

6 Figures; 57 references 


\section{Key points}

- DGK $\zeta$-deficiency in mice results in larger numbers of CD69-positive T cells in bone marrow, with enhanced expression of IFN $\gamma$ and lytic enzymes.

- DGK $\zeta$ loss recapitulates many clinical aspects of human aplastic anemia, identifying a critical hub for immune system-dependent bone marrow failure.

\section{Visual abstract}

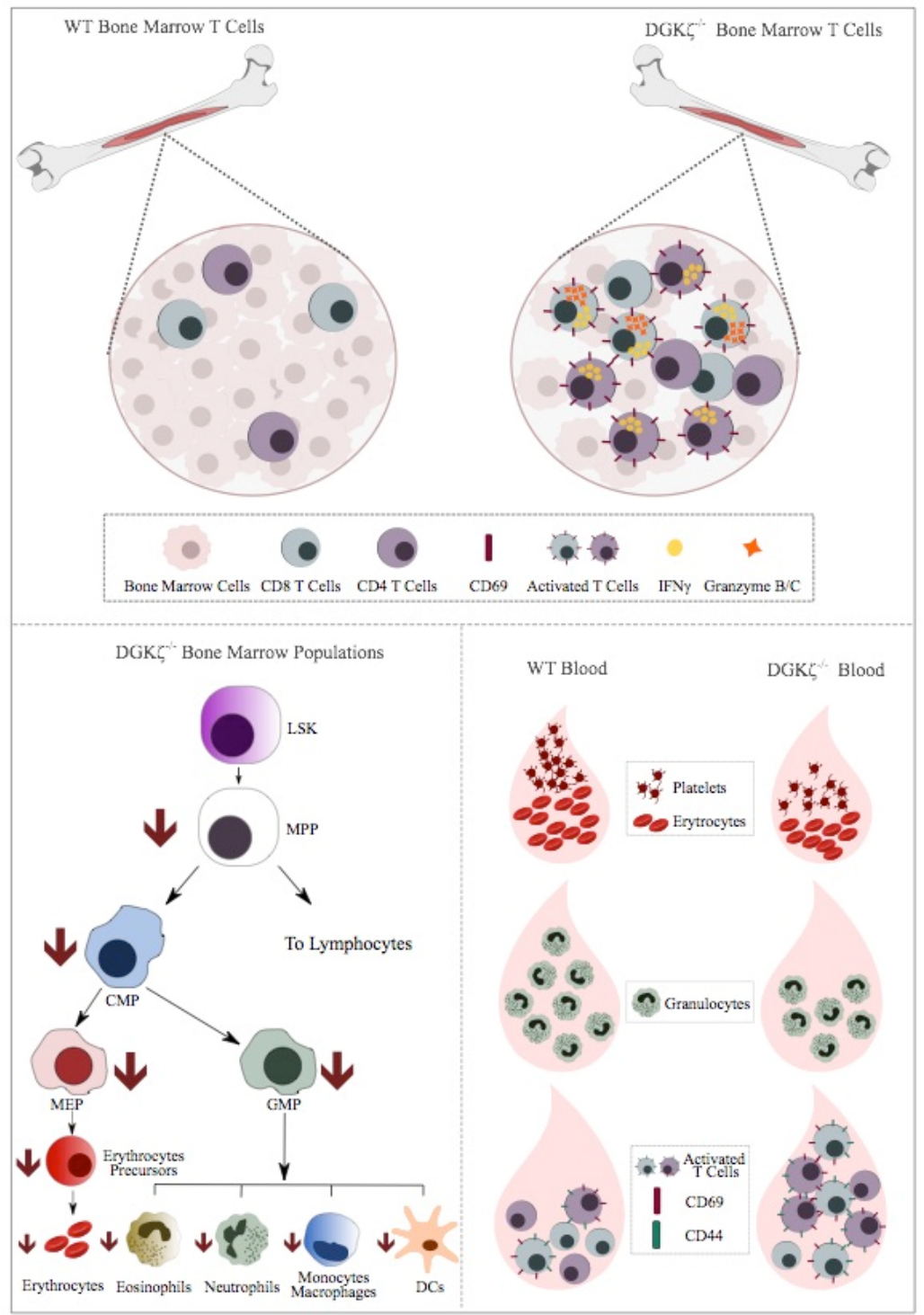




\begin{abstract}
Acquired aplastic anemia (AA) is a rare blood disorder that results from immune-mediated destruction of bone marrow $(\mathrm{BM})$ progenitor cells. Improved understanding of the mechanisms that favor T cell attack in BM could help to improve early diagnosis and disease treatment. Diacylglycerol kinase $\zeta(\mathrm{DGK} \zeta)$ limits $\mathrm{T}$ cell responses through phosphorylation of diacylglycerol into phosphatidic acid. This reaction attenuates diacylglycerol-dependent activation of the Ras/ERK/CD69 and PKC $9 / \mathrm{NFkB}$ pathways in response to antigen. Here we show that, in contrast to the lack of basal activation observed in peripheral lymphoid organs, DGK $\zeta^{-1-}$ mice showed increased numbers of activated $\mathrm{T}$ cells in $\mathrm{BM}$, together with a significant increase in IFN $\gamma$ as well as perforin and granzyme B and $\mathrm{C}$ levels. The enhanced presence of $\mathrm{T}$ cells in $\mathrm{DGK} \zeta^{-/-}$mouse BM correlates with reduced BM cellularity, impaired hematopoiesis, and lower frequency of circulating red cells, granulocytes, and platelets. Our studies coincide with the recent characterization of lower DGK $\zeta$ expression in T cells isolated from the BM of patients with acquired AA, and suggest that limited DGK $\zeta$ expression and/or functions predispose to $\mathrm{T}$ cell-mediated BM destruction. This study identifies the BM as a niche particularly sensitive to DGK $\zeta$ deficiency and indicates that this mouse model could be of interest for studying the mechanism that contributes to AA development.
\end{abstract}




\section{Introduction}

Aplastic anemia (AA), the prototypical bone marrow (BM) failure syndrome, is characterized by peripheral pancytopenia and hypoplastic BM. ${ }^{1}$ Most AA cases are acquired, idiopathic, and result from aberrant activation in the BM of T helper type-1 CD4 ${ }^{+}$(Th1) and cytotoxic $\mathrm{CD}^{+} \mathrm{T}$ cells $(\mathrm{CTL}) .^{2}$ The first choice in AA treatment is allogeneic stem cell transplant using BM cells, or immunosuppressive therapies when transplant is not possible. There is an intensive search for recurrent cytogenetic abnormalities and/or somatic mutations that identify? predisposition to this disease. The identification of biological markers that indicate BM attack could assist in the selection of candidates for transplant, prognosis, and/or the predictive response to immunosuppressive therapies.

Diacylglycerol kinases (DGK) are a family of kinases that phosphorylate diacylglycerol (DAG) to phosphatidic acid (PA). ${ }^{3} \mathrm{DGK} \zeta$ is abundantly expressed in healthy naïve peripheral $\mathrm{T}$ cells, where regulates DAG-dependent activation of Ras/ERK and $\mathrm{PKC} \theta / \mathrm{NF} \kappa \mathrm{B}$ signaling pathways. ${ }^{4}$ DGK $\zeta$ downmodulation in response to antigenic challenge facilitates the correct activation of $\mathrm{T}$ cell helper and cytotoxic functions. Germline-DGK $\zeta$-deficient mice $\left(\mathrm{DGK} \zeta^{-1-}\right)$ have hyperproliferative $\mathrm{T}$ lymphocytes, which are resistant to anergy induction ${ }^{5}$ and show enhanced elimination of xenotransplanted tumors. ${ }^{6-8}$

No human studies to date have described autoimmune-related DGK $\zeta$ alterations. DGK $\zeta^{-1-}$ mice show no overt autoimmune symptoms, which has been attributed to enhanced development and function of regulatory $\mathrm{T}$ cells. ${ }^{9}$ Upregulation of the microRNA miR-34a during T cell activation facilitates DGK $\zeta$ suppression, ${ }^{10}$ whereas Egr2-dependent transcription triggers DGK $\zeta$ induction in tumor-induced $\mathrm{T}$ cell anergy. ${ }^{11}$ Studies in AA patients have shown that mirR34a abundance in T cells is a marker of AA severity, and that higher mirR34a expression correlates with DGK $\zeta$ reduction. ${ }^{12}$ The lesser DGK $\zeta$ abundance in AA patient BM $\mathrm{T}$ lymphocytes suggests a causal relationship between $\mathrm{DGK} \zeta$ deficit, enhanced $\mathrm{T}$ cell 
functions, and BM destruction. This observation in A patients prompted us to investigate the direct consequences of $\mathrm{DGK} \zeta$ genetic deletion in $\mathrm{BM}$ homeostasis. Our studies in $\mathrm{DGK} \zeta^{-/-}$ mice indicate increased presence of activated $\mathrm{T}$ cells in the $\mathrm{BM}$, enhanced erythrocyte destruction, diminished hematopoietic precursor, and peripheral cytopenia. All these abnormalities, characteristic of BM failure, mirrored many of the clinical symptoms described at early stages of AA. Our studies identify an autoimmune disorder as the result of DGK $\zeta$ deficiency and show the utility of $\mathrm{DGK} \zeta^{-/-}$mice as an experimental model for the study of AA onset and development. 


\section{Methods}

Mice. $\mathrm{DGK} \zeta^{-/-}$and DGK $\alpha^{-/-} \mathrm{C} 57 \mathrm{BL} / 6$ mice were kindly donated by Drs. G Koreztky (Weill Cornell Medicine, New York, NY) and XP Zhong (Duke University Medical Center, Durham, NC). Except when indicated (4-5 weeks), animals were used between 6-12 months of age. No sex criteria were established for experiments. All procedures were conducted in accordance with Spanish and European directives and a protocol approved by the CNB/CSIC Ethic Committee for Animal Experimentation (RD53/2013).

BM, lymph nodes, spleen and blood analysis. BM cells were extracted in phosphatebuffered saline (PBS), counted on a Countess II (ThermoFisher), and analyzed by flow cytometry or processed for RNA analysis. Lymph nodes and spleen were removed, disaggregated, and homogenized in $40 \mu \mathrm{m}$ cell strainers (Becton Dickinson), then stained and analyzed by flow cytometry. Blood was collected by heart puncture in EDTA tubes and analyzed on an Abacus Junior Vet blood analyzer $24 \mathrm{~h}$ after extraction, or by flow cytometry.

Histology. Sternum and femur bones were decalcified in 10\% EDTA for $48 \mathrm{~h}$ or 21 days respectively, fixed in $4 \%$ paraformaldehyde, and paraffin-embedded. Tissue sections (5 $\mu \mathrm{m})$ were stained with hematoxylin and eosin (H\&E). BM cell density was analyzed using ImageJ software.

Immunofluorescence. BM cells were lysed with RBC lysis buffer (eBioscience) to remove erythroid cells, fixed in 4\% paraformaldehyde, permeabilized with 0.5\% Triton X-100 (Sigma Aldrich), blocked with $10 \%$ bovine serum albumin (Sigma Aldrich), 0.05\% Triton X-100 in PBS (30 min, RT), and incubated with antibodies to IFN $\gamma$ (Abcam, ab9657) and CD3ع (BD Pharmingen, 550275) $\left(\mathrm{ON}, 4^{\circ} \mathrm{C}\right)$ in a humidified chamber. Antigen was detected using goat anti-rabbit Cy3 (Jackson) and goat anti-Armenian hamster Alexa488 (Abcam, ab173003) (60 min, RT). Images were acquired on an Olympus FV1000 confocal laser scanning microscope, and analyzed with Fiji software. 
Flow cytometry and antibodies. Antibodies used were anti-Ter119-PE, CD8-eFluor450, CD69-PeCy7, Gr1-PeCy7, Ly6G-PE (eBioscience), CD44-APC, (Coulter), CD4-PECy5, CD16/32-FITC, CD34-PE, cKit-APC, Ly6C-FITC, CD11b-PerCP5.5, Ter119-PeCy7, CD11b-PeCy7, CD4-PeCy7, CD8-PeCy7, B220-PeCy7 (BioLegend), CD69-FITC, CD62LFITC, Sca1-biotin, NK1.1-APC, CD11c-biotin (Pharmingen), annexinV-FITC (Southern), annexinV-APC (IMMUNOSTEP) and DAPI-eFluor450. For S1P1 staining, femurs were flushed with fix solution containing $0.1 \%$ paraformaldehyde, $0.5 \%$ BSA, and 2 mM EDTA (Gibco) in PBS as reported. ${ }^{13}$ Cell suspensions were then lysed with RBC lysis buffer (eBioscience), incubated with rat anti-mouse S1P1-APC (R\&D Systems) for $1 \mathrm{~h}$ on ice and washed once. Samples were then incubated $\left(30 \mathrm{~min}, 4^{\circ} \mathrm{C}\right)$ with antibody cocktail to CD4PercP5.5 (BioLegend), CD8-eFluor450 (eBioscience), CD44-FITC (Beckman) and CD69-PE (Pharmingen). Samples were collected on a LSRII (BD Biosciences) and analyzed with FlowJo software (FlowJo LLC, Ashland, OR).

Induction of bone marrow failure (BMF). F1 progeny was generated by crossing C57BL/6 and BALB/c mice. Prior to experiments F1 mice were irradiated ( $3 \mathrm{~Gy},{ }^{137} \mathrm{Cs}$ source); after 5 $\mathrm{h}$, BMF was induced with $5 \times 10^{7}$ splenocytes (intraperitoneal injection) from age- and gender-matched C57BL/6 wild type or $\mathrm{DGK} \zeta^{-/-}$mice, as described. ${ }^{14}$ For survival studies, mice were humanely euthanized when weight loss was less than $80 \%$ of original weight.

cDNA preparation and real time PCR. Total RNA was reverse transcribed using the High Capacity cDNA Archive Kit (PN4368813; Applied Biosystems). Real-time PCR reactions were performed in triplicate with HOT FIREPol EvaGreen qPCR Mix Plus (ROX) (Solis BioDyne) in an Applied Biosystems ABI PRISM 7900HT machine with SDS v2.4 software, using a standard protocol. Results were analyzed by the comparative $\mathrm{Ct}$ method $(\Delta \Delta \mathrm{Ct})$. Expression was normalized using the $\beta$-actin housekeeping gene for each sample. Primers used were: IL-6: 5'-GCTACCAAACTGGATATAATCAGGA-3' and 3'- 
AAGACCTCATGTATCGATG GACC-5';

TNF- $\alpha$ :

5'CCCTCACACTCAGATCATCTTCT-3' and 3'-GACATCGGGTGCA GCATCG-5'. TGF- $\beta$ : 5'-ACCATGCCAACTTCTGTCTG-3'; 3'-AGATGTTGGTTGTGTT GGGC-5'. Primers for IFN $\gamma$ and perforin, ${ }^{15}$ for granzymes A, B and C, ${ }^{16}$ for IL-10 and IL-2, ${ }^{17}$ for KLF-1, cMpl and $\mathrm{p} 57,{ }^{18}$ and for $\beta$-actin ${ }^{19}$ as reported.

Statistical analysis. Data were analyzed using GraphPad Prism 5. Results are represented as mean \pm standard error of the mean (SEM). Normality was analyzed by the KolmogorovSmirnov test. An unpaired two-tailed t-test with $95 \%$ confidence intervals was used for data with normal distribution and equal variances, and an unpaired t-test with Welch's correction for data sets with different variances. The Mann-Whitney U test was used for data with nonnormal distribution. For more than two groups with normal distribution, ANOVA with Bonferroni correction was performed. Kruskal-Wallis test with Dunn's post hoc was applied when two groups with non-normal distribution. Survival statistics were performed with the Gehan-Breslow-Wilcoxon test. Differences were considered non-significant (ns) when $p$ $>0.05$, significant $(*)$ when $p<0.05$, very significant $(* *)$ when $p<0.01$ and extremely significant $(* * *)$ when $p<0.001$. 


\section{Results}

DGK $\zeta$ deficiency in mice causes no gross defects in $\mathrm{T}$ cell development and leads to a slight decrease in mature T cells in spleen, with no signs of activation in basal conditions. ${ }^{5}$ The BM from young (4- to 5-week old) $\mathrm{DGK}^{-1-}$ mice showed similar total numbers of $\mathrm{CD} 4^{+}$ and $\mathrm{CD}^{+}{ }^{+} \mathrm{T}$ cells compared to WT mice (Figure 1A). CD69 is an early activation marker that identifies recent antigen-stimulated $\mathrm{T}$ lymphocytes. ${ }^{20}$ Both $\mathrm{T}$ cell pools in the BM of DGK $\zeta^{-1-}$ mice showed significantly augmented C69 populations with heightened CD69 expression on a per cell basis compared to WT animals (Figure 1B). A greater number of $\mathrm{CD}^{+} 9^{+} \mathrm{T}$ lymphocytes win $\mathrm{DGK} \zeta^{-/-}$mouse BM correlates with observations in AA patients, whose BM $\mathrm{CD} 9^{+} \mathrm{T}$ cell numbers are greater than those of healthy controls. ${ }^{12}$

Expanded numbers of IFN $\gamma$-expressing Th1 T cells is an indicator of $\mathrm{AA}^{2}$ and low IFN $\gamma^{+}$ $\mathrm{T}$ cell frequency correlates with responsiveness to immunosuppressive therapy. ${ }^{21} \mathrm{mRNA}$ expression analysis showed a significant increase in $\mathrm{IFN} \gamma$ abundance in $\mathrm{DGK}^{-1-} \mathrm{BM}$ compared to WT mice (Figure 1C). Additional analysis showed higher expression of perforin and granzymes $\mathrm{A}, \mathrm{B}$ and $\mathrm{C}$ as well as IL-2 and TNF $\alpha$, with reduction in TGF $\beta$ expression (Figure 1C). Greater IFN- $\gamma$ and TNF $\alpha$ expression correlates well with the enhanced skewing toward Th1 phenotypes that results from DGK $\zeta$ deficiency, ${ }^{22}$ and resembles the increased levels of circulating IFN $\gamma$ in AA patients. ${ }^{23}$ Augmented expression of granzymes B and C and perforin in $\mathrm{DGK} \zeta^{-/-}$mouse BM denotes an increase in cytotoxic T cells (CTL) similar to that described in AA patients. ${ }^{24}$ Activated T lymphocytes cause $\mathrm{BM}$ destruction in $\mathrm{AA} ;^{.25} \mathrm{DGK} \zeta^{-1-}$ mice showed reduced BM cellularity (Figure 1D). Analysis of the TER- $119^{+}$erythroid lineage populations did not show differences between $\mathrm{DGK}^{-/-}$and WT mice (Figure 1E). Nonetheless, combined analysis of CD44 expression as a function of cell size in the TER$119^{+}$population $^{26}$ showed lower cell numbers at stage IV in DGK $\zeta^{-/-}$mice (Figure $1 \mathrm{E}$ ). 
The $\mathrm{BM}$ failure in $\mathrm{AA}$ is attributed in great measure to the abnormal presence of inflammatory cytokines that promote HSC differentiation, preventing their continuous selfrenewal. ${ }^{27}$ HSC activity in the $\mathrm{BM}$ is found in a small subset of the lineage marker (Lin) $\mathrm{Sca}^{+}{ }^{+} \mathrm{C}-\mathrm{Kit}^{+}$(LSK) population that gives rise to multipotent progenitors (MMP). ${ }^{28}$ Immunophenotype analysis of HSC by flow cytometry showed no differences in the LSK pool in $\mathrm{DGK} \zeta^{-/-}$mice, with a significant decrease in MMP compared to WT mice (Figure 2A). Further analysis revealed a reduction in the common myeloid progenitors (CMP) as well as megakaryocyte/erythrocyte progenitors (MEP) and granulocyte/monocyte progenitors (GMP) (Figure 2B). Analysis of some key hematopoietic factors showed severely reduced expression of Kruppel-like factor 1 (KLF-1), essential for erythroid lineage commitment and maturation in mice and humans ${ }^{29}$ (Figure 2C). $\mathrm{DGK}^{\zeta^{-1-}}$ mice also showed lower expression of the thrombopoietin (THPO) receptor c-Mpl (Figure 2C). THPO binding to its receptor sustains adult quiescent HSC populations by regulating cyclin-dependent kinase inhibitors including p5 $7^{\text {kip2 }} \cdot 30,31$ Reduced $557^{\text {kip2 }}$ expression pointed to impaired HSC quiescence in DGK $\zeta^{-/-}$mice (Figure 2C).

We analyzed mature myeloid populations using antibodies to target cell surface proteins, in combination with forward $v s$ side scatter (FSC and SSC) parameters as described. ${ }^{32}$ Dendritic subsets $\left(\mathrm{CD} 11 \mathrm{c}^{\mathrm{h}} \mathrm{CD} 11 \mathrm{~b}^{+}\right)$were differentiated from other $\mathrm{CD} 11 \mathrm{~b}^{+}$myeloid subsets and were further analyzed for $\mathrm{NK}_{1} \cdot 1^{+}$natural killer $(\mathrm{NK})$ and $\mathrm{Ly}_{6 \mathrm{G}}{ }^{+}$neutrophil subsets (Figure 2D). Eosinophils (Ly6C ${ }^{\mathrm{Int}} \mathrm{Ly}_{6 \mathrm{G}}^{-} \mathrm{SSC}^{\text {hi }}$ ) were differentiated from the monocyte/macrophage population that were further analyzed for the presence of $\mathrm{Ly}_{6 \mathrm{C}} \mathrm{C}^{+}$and more mature $\mathrm{Ly} 6 \mathrm{C}^{\text {low/neg }}$ populations. ${ }^{33} \mathrm{DGK}^{-/-}$mouse BM showed a substantial reduction in all myeloid populations except NK cells (Figure 2E).

These results demonstrate that young $\mathrm{DGK} \zeta^{-1-}$ mice have activated $\mathrm{T}$ cells in $\mathrm{BM}$ and a concurrent reduction in precursors of erythroid and myeloid populations. Lineage tracing 
experiments show that HSC produce the majority of conventional myeloid cells and platelets within 8 months, approximately half of the mouse lifespan. ${ }^{34}$ We thus explored the evolution of $\mathrm{BM}$ populations in adult (6-12 months) $\mathrm{WT}$ and $\mathrm{DGK} \zeta^{-/-}$mice. Total $\mathrm{CD} 4^{+} \mathrm{T}$ cell numbers in the $\mathrm{BM}$ from $\mathrm{DGK}^{-\zeta^{--}}$mice were elevated compared to those in WT mice (Figure 3A). CD69 analysis confirmed increase both in the total numbers of CD69 positive and the CD69 expression in CD4 and CD8 $\mathrm{T}$ cell populations (Figure 3B). In addition to acting as a $\mathrm{T}$ cell activation marker, CD69 functionally promotes BM retention by binding to and sequestering the sphingosine-1-phosphate receptor (S1P1), necessary for BM egress. ${ }^{35}$ In accordance, the percentage of $\mathrm{S}_{1} \mathrm{P}^{+} \mathrm{CD} 4^{+} \mathrm{T}$ cells was lower in $\mathrm{DGK} \zeta^{-/-}$compared to controls. A lesser, nonsignificant tendency was observed in $\mathrm{CD}^{+} \mathrm{T}$ cells (Figure 3C).

Similar to that observed in young mice, mRNA analysis indicated augmented expression of IFN $\gamma$ and granzymes B and C (Figure 3D). No differences were observed for IL-2, TNFa, TGF $\beta$ and IL-10, except for lower IL-6 expression (Figure 3E). Immunofluorescence analysis confirmed increased mean fluorescence intensity (MFI) of IFN $\gamma$ in $\mathrm{CD}^{+}$cells from $\mathrm{BM}$ of $\mathrm{DGK}^{-/-}$compared to WT mice (Figure $\left.3 \mathrm{~F}\right)$.

Analysis of BM from mature $\mathrm{WT}$ and $\mathrm{DGK} \zeta^{-/-}$showed substantial loss of cellularity (Figure 4A) that correlated at this age with a marked reduction of the erythroid TER-119+ population $^{36}$ (Figure 4B). Annexin V staining suggested a higher apoptosis rate in $\mathrm{DGK} \zeta^{-1-}$ TER-119 ${ }^{+}$erythrocytes compared to WT mice (Figure 4B). Based on CD44 vs. FSC gating for erythroid differentiation, $\mathrm{DGK} \zeta^{-/-}$showed reduced cell numbers at all differentiation stages (Figure 4C). Annexin V staining for apoptosis detection was higher at stage I, the earliest progenitors, and at stage IV, where erythroid precursors show the greatest sensitivity to apoptotic cell death ${ }^{37}$ (Figure 4C). Analysis of cells from the myeloid lineage in DGK $\zeta^{-1-}$ mice showed reduced numbers of neutrophils and monocytes/macrophage populations (Figure 4D). 
DGK $\alpha$ is another DGK family member expressed highly in T lymphocytes and has partially redundant functions in the control of Ras/ERK signals downstream of the TCR. ${ }^{4}$ At difference from the case for DGK $\zeta, \mathrm{DGK} \alpha^{-/-}$mice showed normal numbers of BM CD4 and CD8 T cells (Suppl Figure 1A) with no differences in CD69 expression (Suppl Figure 1B). Ter $119^{+}$populations were not altered (Suppl. Figure 1C), with similar cell numbers at all differentiation stages (Suppl. Figure 1D). These results strongly suggest an isoform-specific DGK $\zeta$ contribution limiting $\mathrm{T}$ cell activation at the BM.

Immune-dependent destruction of BM precursors together with continuous differentiation eventually translates into peripheral cytopenia in AA patients. Blood analysis of $\mathrm{DGK}^{-/-}$mice showed reduction in RBC counts, as well as decreased hematocrit and hemoglobin content compared to WT mice (Figure 5A). Similar lymphocyte counts (Figure 5B) contrasted with severe reduction in circulating granulocytes and platelets, as anticipated from BM analysis (Figure 5C). These data fully agree with the impaired generation of precursors, erythrocyte and myeloid populations, and correlate with clinical symptoms observed in AA patients.

As human studies show that the most activated T cells enter the circulation, ${ }^{38}$ we analyzed the activation profile of $\mathrm{WT}$ and $\mathrm{DGK} \zeta^{-/-}$peripheral blood cells (PBL). DGK $\zeta^{-/-}$mice showed a higher percentage of circulating CD4 and CD8 T cells (Figure 5D), with large increase in $\mathrm{CD}^{+} 9^{+} \mathrm{CD}^{+}$and $\mathrm{CD}^{+} \mathrm{T}$ cells (Figure 5E). Based on L-selectin (CD62L) and CD44 expression, we analyzed blood for $\mathrm{CD} 62 \mathrm{~L}^{\mathrm{h}} \mathrm{CD} 44^{\text {lo }}$ naive $(\mathrm{TN}), \mathrm{CD} 62^{\mathrm{lo}} \mathrm{CD} 44^{\mathrm{h}}$ effector memory (TEM) and CD62 ${ }^{\mathrm{h}} \mathrm{CD} 44^{\mathrm{h}}$ central memory (TCM) T cells (Figure 5F); in agreement with heightened expression of the activation marker CD69, blood analysis from $\mathrm{DGK} \zeta^{-/-}$mice showed reduced abundance of TN populations with an increased percentage of TEM (Figure 5F) and TCM CD4 ${ }^{+}$T compared to WT mice (Figure 5F). In agreement with other reports, ${ }^{5}$ CD69 expression was similar in $\mathrm{DGK}^{-/-}$and WT splenocytes and lymph nodes (Figure 5G). The analysis of DGK $\zeta^{-1-} \mathrm{PBL}$ reflects the activation T cell phenotype observed in the BM. The 
activation phenotype is reminiscent of the reduced frequency of $\mathrm{TN} \mathrm{CD} 4^{+} / \mathrm{CD}^{+}$cells $^{39}$ and the increase percentages of $\mathrm{CD} 4^{+}$and $\mathrm{CD} 8^{+}$TEM subsets ${ }^{40}$ that are described in PBLs of AA patients.

All these experiments suggested direct correlation between DGK $\zeta$ loss and enhanced $\mathrm{T}$ cell-mediated destruction of the BM. To further demonstrate a causal relationship between DGK $\zeta$ deficiency in the $\mathrm{T}$ cell compartment and BM damage, we used a well-characterized murine model of immune-dependent BM failure. ${ }^{14}$ Severe AA was induced via sublethal irradiation of F1 hybrid mice, followed by adoptive transfer of WT or DGK $\zeta^{-1-} \mathrm{C} 57 \mathrm{BL} / 6$ splenocytes (Figure 7A). All infused animals showed symptoms rapidly and were sacrificed between 14 and 17 days (Figure 7B). In accordance with the higher IFN $\gamma$ serum concentrations detected in murine lymphocyte infusion-induced BM failure models, ${ }^{41}$ the $\mathrm{BM}$ of mice analyzed 7 days after infusion with WT splenocytes showed enhanced IFN $\gamma$ expression compared to irradiated control animals (Figure 7C). Augmented granzyme A and IL-2 expression was in agreement with the massive infiltration of $\mathrm{CD}^{+}$( $\mathrm{NK}$ and $\mathrm{T}$ cells) described in this infusion model. ${ }^{41}$ Compared to mice infused with WT splenocytes, hosts receiving $\mathrm{DGK} \zeta^{-/-}$cells showed higher expression of perforin and granzymes $\mathrm{A}$ and $\mathrm{B}$ indicative of strong cytotoxic function (Figure 7C). The lack of IL-2 increase observed in hosts infused with DGK $\zeta$-deficient cells, contrasted with enhanced expression of TNF- $\alpha$ and IL-6 (Fig 7C). In mouse models of graft-versus-host disease (GVHD), TNF $\alpha$ production correlates with the destructive phase of the disease. ${ }^{42}$ Enhanced IL- 6 production is also an important factor in the severity of murine GVDH pathology. ${ }^{43}$ In accordance with the recognized contribution of $\mathrm{TNF} \alpha$ and IL-6, the extent of BM destruction was higher in F1 mice that received DGK $\zeta^{-/-}$cells compared to those infused with WT cells (Figure 7D). 


\section{Discussion}

Studies in animal models have shown that antigen recognition in the absence of DGK $\zeta$ results in stronger Ras/PKC $\theta$ activation, leading to enhanced AP-1/NFkB-regulated transcription. ${ }^{44}$ This promotes a CD4 Th1/ Th2 skew that provides DGK $\zeta^{-/-}$mice with enhanced anti-viral responses, ${ }^{5}$ granting protection against allergic asthma. ${ }^{22}$ DGK $\zeta$ deficiency also potentiates cytotoxic programs in $\mathrm{CD}^{+} \mathrm{T}$ and NK cells, boosting antitumor functions in an antigen-dependent ${ }^{45}$ and -independent manner. ${ }^{6,46}$ These and other studies prompted a growing interest in DGK $\zeta$ as a pharmacological target with immunomodulator abilities. A central issue when considering the therapeutic potential of negative regulators of $\mathrm{T}$ cell function is the risk of unleashing adverse autoimmune responses. Characterization of autoimmune disease symptoms in $\mathrm{DGK}^{-1-}$ mice is critical to fully assessing the therapeutic potential of this enzyme.

Our studies identify abnormal accumulation of CD69-positive $\mathrm{T}$ cells in the BM of untreated DGK $\zeta^{-/-}$mice, a situation reminiscent of the enhanced CD69 expression observed in BM T lymphocytes from AA patients. The lower cellularity, impaired erythropoiesis, and deficient progenitor population numbers found in $\mathrm{DGK} \zeta^{-/-}$mouse $\mathrm{BM}$ suggest immunedependent BM failure similar to that described in AA. The observation of diminished DGK $\zeta$ expression in the $\mathrm{T}$ cells from the $\mathrm{BM}$ of $\mathrm{AA}$ patients ${ }^{12}$ further reinforces our observations and suggests a possible role for $\mathrm{DGK} \zeta$ in limiting T cell-dependent BM destruction.

The finding of $\mathrm{CD} 69^{+} \mathrm{T}$ cells in the $\mathrm{BM}$ of $\mathrm{DGK} \zeta^{-/-}$mice at a very young age, together with the presence of Th1 and cytotoxic cytokines, suggest early presence of activated T cells. CD69 is an activation marker that is induced rapidly after antigen recognition and decays very rapidly in peripheral cells. In activated CD4 T cells, CD69 expression attenuates S1P1 expression and promotes homing into the BM, where CD4 $\mathrm{T}$ cells evolve into memory subsets. $^{47}$ As a result, the $\mathrm{BM}$ is recognized as a central niche for long-term homing of 
memory T cells. ${ }^{48}$ The ability of CD69 to favor BM homing for CD4 T cells and attenuate $\mathrm{S} 1 \mathrm{P} 1$ expression coincides with the greater $\mathrm{CD} 4 \mathrm{~T}$ cell retention observed in the $\mathrm{BM}$ of DGK $\zeta^{-/-}$mice. DGK $\zeta$ deficiency correlates with enhanced CD69 expression in CD4 and CD8 T cells. ${ }^{44}$ The reduction in naive populations and concomitant increase in memory $\mathrm{T}$ cells in PBL from $\mathrm{DGK} \zeta^{-/-}$mice confirms self-activation, in accordance with the direct communication between the BM and peripheral blood.

Immune-dependent $\mathrm{BM}$ destruction in $\mathrm{AA}$ is attributed both to the direct and indirect effects of Th1 and CTL on HSC and other hematopoietic lineages. ${ }^{49}$ In healthy conditions, elevation of inflammatory cytokines such as IFN $\gamma$ induce rapid differentiation of HSC to the myeloid lineage to respond to infections. Abnormal, chronic IFN $\gamma$ elevation in AA impairs HSC continuous self-renewal leading to loss of stem precursors.$^{27}$ The analysis of stem cell populations in $\mathrm{DGK} \zeta^{-/-}$mice reveals an abnormal, high elevation of IFN $\gamma$ concomitant with a significant decrease in all precursor populations and myeloid mature cells. In agreement, DGK $\zeta^{-/-}$mice have reduced numbers of circulating red cells, platelets, monocytes, and granulocytes. In addition to the loss of self-renewal abilities of the stem subsets, immunedependent BM destruction is also linked to the direct induction of apoptosis. The increased apoptosis of erythroblasts observed even at a very early age, together with the lowered expression of cell cycle inhibitors probably linked to defective TPHO functions indicates that these are not opposite alternatives. These data coincides with the analysis of CD $34^{+}$cells from severe pediatric AA patients, which shows higher expression of apoptotic-related genes and an enhanced IFN $\gamma$ signature. ${ }^{50} \mathrm{DGK}^{-1-}$ mice show partial $\mathrm{BM}$ aplasia and diminished circulating platelets and granulocytes, but not severe anemia. It is plausible that low, chronic $\mathrm{T}$ cell activation leads to $\mathrm{T}$ cell exhaustion in a manner similar to the exhausted hyporesponsive $\mathrm{T}$ cells found in the BM of IFN $\gamma$-induced murine models of AA. ${ }^{51}$ 
The phenotype of $\mathrm{DGK}^{-/-}$mice suggests $\mathrm{BM}$ destruction by autoreactive $\mathrm{T}$ cells. In agreement, infusion of $\mathrm{DGK} \zeta^{-/-} \mathrm{T}$ splenocytes in histocompatibility-mismatched hosts accelerated BM damage when compared with splenocytes from WT mice. Cytokine analysis showed enhanced TNF $\alpha$ and IL-6 production in hosts infused with DGK $\zeta^{-/-}$cells. In GVHD models, transient IFN $\gamma$ production associates with the initial highly proliferative phase whereas TNF $\alpha$ production correlates with the later more destructive phase of the disease. ${ }^{42}$ Our results suggest a temporality in the induction of BM failure as the result of a GVHD-like response; they suggest that DGK $\zeta$ loss accelerates the onset of the reaction from the initial proliferative phase to the final destructive phase. This hypothesis coincides with recent studies in murine models of acute AA showing that TNF $\alpha$, which is generated by host macrophages in response to infused T cells, accelerates immune-mediated BM destruction. ${ }^{53}$ Reduced IL-2 expression observed in mice that receive DGK $\zeta$-deficient cells is consistent with rapid onset of activation, leading to functional decline of antigen-specific effector $\mathrm{T}$ cells that could result in their depletion. Exhaustion of rapidly expanding effector $\mathrm{T}$ cell populations is said to explain stronger antitumor effects in xenotransplanted DGK $\zeta^{-/-}$mice. ${ }^{6}$ Little or no IFN $\gamma$ production by BM T cells is also observed in very severe cases of AA, and is predictive of a lack of response to immunosuppressive therapy. ${ }^{21}$ Progressive $\mathrm{T}$ cell exhaustion would coincide with the lack of high IL-2 and TNF $\alpha$ expression observed in mature mice. It would also conform to reduced expression of IL-6, a pro-inflammatory cytokine that, as described for IFN $\gamma$ and TNF $\alpha$, regulates HSC differentiation. ${ }^{52}$

Despite intensive studies, understanding of the autoimmune mechanism in AA remains limited. Pesticides, toxic chemicals, and viral infections are hypothesized to confer higher risk, but acquired AA is largely considered idiopathic and the autoantigen remains unknown. We found no sex differences in the phenotype of $\mathrm{DGK} \zeta^{-/-}$mice, whereas enhanced BM failure in older mice suggests cumulative damage. A progressive loss of BM function would agree 
with recent studies that cite normal platelet counts in $\mathrm{DGK} \zeta^{-1-}$ mice around 10 weeks of age. ${ }^{54}$ In contrast observations in older animals, our analysis confirms normal platelet counts between 10-15 weeks (not shown). The reported abnormal platelet responses ${ }^{54}$ could nonetheless be a result of defective differentiation. In this regard, all components of the trimeric GPIB/GPIX/GPV complex as well as GPVI, the collagen receptor on platelets, appear markedly downregulated in $\mathrm{CD}_{3} 4^{+}$gene profiling from pediatric severe AA patients. ${ }^{50}$

In summary, our study demonstrates that DGK $\zeta$ protects the BM from autoimmunemediated destruction, and suggests that $\mathrm{DGK}^{-/-}$mice are a useful model to further explore the mechanisms that trigger this disease. Detection of DGK $\zeta$ expression could also be an important biomarker of the T cell function in AA patients. Finally, a better understanding of the mechanism by which DGK $\zeta$ protects the BM from autoimmune destruction could help to avoid the risks of aplastic anemia induced by treatment with immune checkpoint inhibitors. $^{55-57}$ 


\section{Acknowledgments}

We thank Cathy Mark for excellent editorial assistance and IM group members for helpful discussion. EA holds a predoctoral fellowship from the Spanish Ministry of Education. This work was supported in part by grants from the Aplastic Anemia and MDS International Foundation (AAMDSIF OPE01644), Spanish Ministry Economy and Competitiveness cofinanced by the European Regional Development Fund (BFU2016-77207-R) and the Madrid regional government (IMMUNOTHERCAM Consortium S2010/BMD-2326) to IM.

Authorship contributions: IM, EA and MMS designed the research and wrote the manuscript; EA, MMS, MLS and RL performed the experiments; MMS and EA analyzed the results; MMS and EA designed the figures.

Disclosure of conflicts of interest: The authors have no conflict of interests. 


\section{Figure 1. Analysis of BM T cells from DGK $\zeta$ deficient mice.}

$\mathrm{BM}$ cells from $\mathrm{WT}$ and $\mathrm{DGK} \zeta^{-/-}$mice were flushed from tibias and femurs and processed for flow cytometry analysis. (A) Quantification of $\mathrm{CD} 4^{+}$and $\mathrm{CD} 8^{+} \mathrm{T}$ cells counts in the BM of 4to 5- week old mice (gated in total cells). (B) Left, representative histograms of CD69 expression gated on $\mathrm{CD}^{+}$or $\mathrm{CD}^{+} \mathrm{T}$ cell populations. Middle, total counts of activated $\mathrm{T}$ cells $\mathrm{CD} 69^{+} \mathrm{CD}^{+}$and $\mathrm{CD} 69^{+} \mathrm{CD}^{+}$cells. Right, mean fluorescence intensity (MFI) of CD69 in $\mathrm{CD}^{+}$and $\mathrm{CD}^{+}$populations. (C) mRNA expression was analyzed from total BM cells by RT-qPCR. Top, expression of IFN $\gamma$, perforin and granzymes (Grz.). Bottom, mRNA levels of IL-2, TNF $\alpha$, TGF $\beta$ and IL-10. (D) Left, femur sections were fixed, and H\&E stained. Images show central area of each section (200x). MiddleCenter, quantification of the percentage of area covered by cells. Right, quantification of total BM cells by TrypanBlue exclusion. (E) Left, quantification of total erythroid cells in WT and DGK $\zeta^{-/-}$mice by Ter119 expression. Right, analysis of erythroid differentiation. A. Mean \pm SEM. $n=6 /$ genotype. CD4 ${ }^{+}$. Unpaired t-test. CD8 ${ }^{+}$. Mann-Whitney test. B. Mean \pm SEM. n=6/genotype. Unpaired t-test. C. Mean \pm SEM. WT $\mathrm{n}=4 ; \mathrm{DGK}^{-/-} \mathrm{n}=5$. IFN $\gamma$, perforin and Grz. C. Unpaired t-test with Welch's correction. Grz. A, Grz. B, IL-2, TNF $\alpha$ and TGF $\beta$. Unpaired t-test. IL-10. Mann-Whitney test. Data were acquired in two independent experiments. D. Mean \pm SEM. Left and center, four sections/mouse; WT $\mathrm{n}=4, \mathrm{DGK}_{\zeta^{--}} \mathrm{n}=5$. Unpaired t-test. For total cellularity, WT $\mathrm{n}=14$, DGK $\zeta^{-/-} n=18$. Unpaired t-test. E. Mean \pm SEM. WT $n=7, D G K \zeta^{-/-} n=8$. E. Mann-Whitney test. Data were acquired in two independent experiments.

\section{Figure 2. DGK $\zeta^{-/-}$mice show defects in HSCs and myeloid development in the BM.}

(A) Left, representative flow cytometry dot plots of cKit and Sca1. Right, quantification of total of LSK cells $\left(\mathrm{Lin}^{-} \mathrm{cKit}^{+} \mathrm{Sca}^{+}\right.$) (gated on $\mathrm{Lin}^{-} \mathrm{BM}$ cells), and multipotent progenitors (MP) $\left(\mathrm{Lin}^{-} \mathrm{cKit}^{+} \mathrm{Sca1}^{-}\right)$(gated on $\mathrm{Lin}^{-}$cells). (B) HSCs composition was gated on $\mathrm{Lin}^{-} \mathrm{BM}$ 
cells by flow cytometry. Left, representative dot plots of CD16/32 and CD34. Right, quantification of common myeloid progenitors (CMP) $\left(\mathrm{Lin}^{-} \mathrm{cKit}^{+} \mathrm{Sca}^{-} \mathrm{CD} 34^{+} \mathrm{CD} 16 / 32^{\mathrm{int}}\right)$, granulocyte/monocyte progenitors (GMP) $\left(\mathrm{Lin}^{-} \mathrm{cKit}^{+} \mathrm{Scal}^{-} \mathrm{CD} 34^{+} \mathrm{CD} 16 / 32^{\mathrm{hi}}\right)$, and megakaryocyte/erythrocyte progenitors (MEP) $\left(\mathrm{Lin}^{-} \mathrm{cKit}^{+} \mathrm{Sca}{ }^{-} \mathrm{CD} 34^{-} \mathrm{CD} 16 / 32^{\mathrm{lo}}\right.$ ) (gated on MP). (C). mRNA was purified from total BM cells and KLF1, cMpl and p57 expression was analyzed by RT-qPCR. (D) Flow cytometry dot plots of gating strategy followed for myeloid characterization. (E) Quantification of total dendritic cells $\left(\mathrm{CD} 11 \mathrm{~b}^{+} \mathrm{CD} 11 \mathrm{c}^{+}\right)$, natural killer cells (NK1.1 ${ }^{+} \mathrm{Ly}_{6 \mathrm{G}}^{-}$) (gated on $\mathrm{CD} 11 \mathrm{~b}^{\text {low/high }} \mathrm{CD} 4^{-} \mathrm{CD} 8^{-} \mathrm{B} 220^{-}$), neutrophils $\left(\mathrm{NK} 1.1^{-} \mathrm{Ly}^{6} \mathrm{G}^{+}\right.$) (gated on $\left.\mathrm{CD} 11 \mathrm{~b}^{\text {low/high }} \mathrm{CD} 4^{-} \mathrm{CD}^{-} \mathrm{B} 220^{-}\right)$, eosinophils $\left(\mathrm{Ly} 6 \mathrm{C}^{\mathrm{dim}}\right)$ (gated on $\mathrm{CD} 11 \mathrm{~b}^{\text {low/high }}$

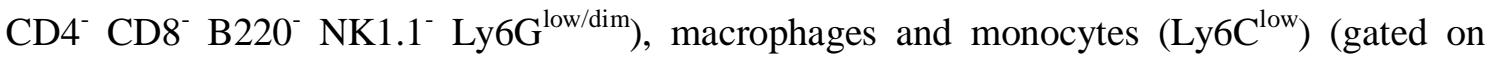
$\left.\mathrm{CD} 11 \mathrm{~b}^{\text {low/high }} \mathrm{CD}^{-} \mathrm{CD}^{-} \mathrm{B}^{-} 20^{-} \mathrm{NK}^{-1} 1^{-} \mathrm{Ly} 6 \mathrm{G}^{\text {low/dim }}\right)$, and inflammatory macrophages

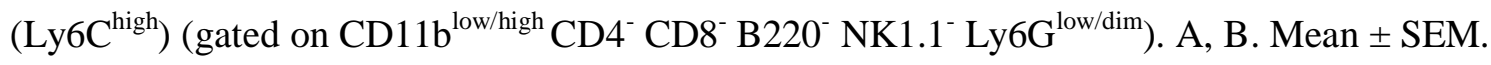
WT $n=5 ; D G K \zeta^{--} n=7$. Unpaired $t$ test. Data were acquired in two independent experiments. C. Mean \pm SEM. WT $n=4 ; D G K \zeta^{-/-} n=5.2^{-\Delta \Delta C t} p 57$. Unpaired t-test with Welch's correction. $2^{-\Delta \Delta \mathrm{Ct}}$ KLF1 and cMpl. Unpaired t-test. D, E. Mean \pm SEM. n=7/genotype. Unpaired t-test. Data were acquired in two independent experiments.

\section{Figure 3. Analysis of BM T cells of mature $D G K \zeta^{-/-}$mice}

(A) Left, flow cytometry dot plots of CD4 and CD8 T cell populations in total BM. Right, quantification of total CD4 and CD8 T cells. (B) Left, representative histograms of CD69 expression gated either on $\mathrm{CD}^{+}$or $\mathrm{CD}^{+} \mathrm{T}$ cell populations. Middle, total numbers of activated T cells $\mathrm{CD} 69^{+} \mathrm{CD} 4^{+}$and $\mathrm{CD} 69^{+} \mathrm{CD} 8^{+} \mathrm{T}$ cells. Right, MFI of CD69 gated on $\mathrm{CD} 4^{+}$or $\mathrm{CD}^{+} \mathrm{T}$ cells $(\mathbf{C}) \mathrm{S} 1 \mathrm{P} 1$ expression was analyzed in $\mathrm{T}$ cells from $\mathrm{WT}$ and $\mathrm{DGK} \zeta^{-/-}$mice by flow cytometry. Left, representative flow cytometry dot plots of CD69 vs S1P1. Right, percentages of $\mathrm{CD} 9^{+}$and $\mathrm{S} 1 \mathrm{P} 1^{+} \mathrm{T}$ cells $\left(\right.$ gated on $\mathrm{CD} 4^{+}$or $\left.\mathrm{CD} 8^{+}\right)$. (D, E) mRNA expression 
of IFN $\gamma$, perforin (Perf), granzymes (Grz) and interleukin (IL) 2, 6, 10 and TNF $\alpha$ was analyzed by RT-qPCR from total BM lysates. (F) CD3 $\varepsilon$ and intracellular IFN $\gamma$ were stained and analyzed by confocal microscopy in total BM cells. Bottom, quantification of MFI of IFN $\gamma$ in CD3 $\varepsilon$ cells. A, B. Data shown as mean \pm SEM. WT $n=13$; DGK $\zeta^{-1-} n=14$. A. MannWhitney test. B. Unpaired t-test with Welch's correction (for $\mathrm{CD} 69^{+} \mathrm{CD} 4^{+}$and $\mathrm{CD} 69^{+} \mathrm{CD} 8^{+}$), Mann-Whitney test (for MFI CD69 in CD4) and unpaired t test (for MFI CD69 in CD8). Data were acquired in three independent experiments. C. Mean \pm SEM. $n=15 /$ genotype. For $\%$ CD69. Unpaired t test with Welch's correction. For \% S1P1. Unpaired t test. Data were acquired in three independent experiments. D, E. Mean \pm SEM. n=10/genotype. Perf., Grz. A, B, C, IL-2 and IL-10. Mann-Whitney test. TNF $\alpha$, IL-6 and TGF $\beta$. Unpaired t-test with Welch's correction. Data were acquired in three independent experiments. F. Mean \pm SEM. Eleven images/mouse. n=3/genotype. Mann-Whitney test.

Figure 4. DGK $\zeta^{-/-}$mice show signs of $B M$ aplasia and defects in the erythroid compartment.

(A) Left, femurs from $\mathrm{WT}$ and $\mathrm{DGK} \zeta^{-/-}$mice were fixed and H\&E stained. Images show central area of each section (200x). Top right, quantification of the percentage of area covered by cells in BM samples. Bottom right, BM cells obtained from tibias and femurs of WT and $\mathrm{DGK} \zeta^{-/-}$mice were quantified by TrypanBlue exclusion. (B) Total erythroid lineages and different erythroid populations within the BM were analyzed by flow cytometry. Top, total erythroid counts $\left(\right.$ Ter1 $\left.19^{+}\right)$(gated on total cells). Bottom, percentage of cell death Ter119 population $\left(\%\right.$ annexin $\mathrm{V}^{+}$cells $+\%$ annexin $\mathrm{V}^{+} \mathrm{DAPI}^{+}$cells $)$. (C) Left, representative dot plots of CD44 and FSC populations in WT and DGK $\zeta^{-/-}$mouse BM (gated on Ter119 ${ }^{+}$cells). Top right, quantification of erythroid populations (in Ter $119^{+}$cells). Bottom right, percentage of cell death $\left(\%\right.$ annexin $\mathrm{V}^{+}$cells $+\%$ annexin $\mathrm{V}^{+} \mathrm{DAPI}^{+}$cells $)$for the different erythroid 
populations. (D) Quantification of total dendritic cells (DC), natural killer cells (NK), neutrophils, macrophages $(\mathrm{M} \phi) /$ monocytes, eosinophils and inflammatory $\mathrm{M} \phi$ in the $\mathrm{BM}$ of WT and DGK $\zeta^{-/-}$mice following the gating strategy depicted in Figure 2. A. Data shown as mean \pm SEM. Three sections/mouse; n=3/genotype. Mann-Whitney test. For total cellularity, n=14/genotype. Unpaired t-test with Welch's correction. B. Mean \pm SEM. Top, n=14/genotype. Mann-Whitney test. Bottom, n=3/genotype. Unpaired t-test. C. Mean \pm SEM. Top right, $n=14 /$ genotype. Mann-Whitney test. Bottom right, $n=3 /$ genotype. Unpaired t-test. Data were acquired in three independent experiments. D. Data shown as mean \pm SEM. $\mathrm{n}=3$ /genotype. Unpaired t-test. Data were acquired in a single experiment.

\section{Figure 5. Analysis of peripheral blood of DGK $\zeta^{-/-}$mice}

Blood was collected by heart puncture from $\mathrm{WT}$ and $\mathrm{DGK} \zeta^{--}$mice and analyzed on an Abacus Junior Vet blood analyzer or processed for flow cytometry. (A) Left, analysis of total circulating red blood cells. Center, hematocrit analysis. Right, hemoglobin quantification. (B) Total circulating lymphocytes. (C). Left, analysis of total granulocytes. Right, analysis of circulating platelets. (D) Flow cytometry analysis of blood samples for circulating $\mathrm{T}$ lymphocyte characterization. Percentages of $\mathrm{CD}^{+}$and $\mathrm{CD}^{+} \mathrm{T}$ cells (gated on total cells). (E) Percentages of $\mathrm{CD}^{+} 9^{+}$(gated on $\mathrm{CD}^{+}$or $\mathrm{CD}^{+}$). (F) Left, representative flow cytometry dot plots of CD62L and CD44 cells gated on CD4 (top) or CD8 (bottom). Right, quantification of percentages of $\mathrm{CD} 62 \mathrm{~L}^{\text {high }} \mathrm{CD} 44^{\text {low }}$ (naïve), $\mathrm{CD} 62 \mathrm{~L}^{\text {high }} \mathrm{CD} 44^{\text {high }}$ (central memory, $\mathrm{T}_{\mathrm{cm}}$ ) and CD62L ${ }^{\text {low }} \mathrm{CD} 44^{\text {high }}$ (effector memory, $\mathrm{T}_{\mathrm{em}}$ ) gated on $\mathrm{CD}^{+}$or $\mathrm{CD} 8^{+}$. (G) $\mathrm{CD} 69$ expression was analyzed in spleen and lymph nodes. A-C. Mean \pm SEM. n=14/genotype. A. Left, Unpaired ttest. Center, Mann-Whitney test. Right, Unpaired t-test with Welch's correction. B. Unpaired t-test with Welch's correction. C. Left, Unpaired t-test. Right, Mann-Whitney test. Data were acquired in three independent experiments. D-F. Mean \pm SEM. $n=13$ /genotype. D. Percentage 
of CD4. Mann-Whitney test. Percentage of CD8. Unpaired t-test. E. Percentage of CD69 (CD4). Unpaired t-test. Percentage of CD69 (CD8). Mann-Whitney test. Percentage of CD62L ${ }^{\text {high }} \mathrm{CD} 44^{\text {low }}$ (naïve), CD62L ${ }^{\text {high }} \mathrm{CD} 44^{\text {high }}$ (central memory, $\mathrm{T}_{\mathrm{cm}}$ ) and $\mathrm{CD} 62 \mathrm{~L}^{\text {low }} \mathrm{CD} 44^{\text {high }}$ (effector memory, $\mathrm{T}_{\mathrm{em}}$ ) in CD4. Mann-Whitney test. In CD8. Mann-Whitney test. Data were acquired in four independent experiments. G. Mean \pm SEM. $n=3 /$ genotype. Unpaired t-test.

\section{Figure 6. DGK $\zeta$ deficiency enhances immune-dependent BM destruction}

(A) Scheme for the generation of a mouse model of severe aplastic anemia: C57BL/6 (Hb/b) and $\mathrm{BALB} / \mathrm{c}(\mathrm{Hd} / \mathrm{d})$ mice were crossed and $\mathrm{F} 1$ progeny $(\mathrm{Hb} / \mathrm{d})$ mice were sublethally irradiated $(\gamma \mathrm{R})$ and infused with $5 \times 10^{7} \mathrm{WT}$ or $\mathrm{DGK} \zeta^{-/-} \mathrm{C} 57 \mathrm{BL} / 6$ splenocytes by i.p. injection. (B) Kaplan-Meier survival curve $($ day +17$)$ estimates percentage of living mice after aplastic anemia induction with WT or DGK $\zeta^{-1-}$ C57BL/6 splenocytes. (C) mRNA expression of Grz A, B, C, perforin, IFN $\gamma$, IL-2, TNF $\alpha$, IL-10 and IL-6 was analyzed by RT-qPCR on day +7 after bone marrow failure induction. (D) Left, sternums from F1 hybrid mice were fixed and $\mathrm{H} \& \mathrm{E}$ stained on day +17 post disease induction. Images show central area of each section (200x). Right, quantification of the percentage of area covered by cells in sternum samples after aplastic anemia induction. B. N=10/genotype; control PBS n=-2. Gehan-BreslowWilconxon test. Data were acquired in two independent experiments. C. Mean \pm SEM. $n=3 /$ genotype. One-way ANOVA with the Bonferroni post hoc test. D. Mean \pm SEM. Three sections/mouse; WT/WT n=8; $\mathrm{DGK} \zeta^{-/-} / \mathrm{WT} n=10$; control PBS $\mathrm{n}=2$. Kruskal-Wallis test and Dunn's post hoc. One representative image of each sample is shown. Data were acquired in two independent experiments. 


\section{Bibliography}

1. Young NS, Scheinberg P, Calado RT. Aplastic anemia. Curr Opin Hematol. 2008;15(3):162-168.

2. Solomou EE, Keyvanfar K, Young NS. T-bet, a Th1 transcription factor, is up-regulated in T cells from patients with aplastic anemia. Blood. 2006;107(10):3983-3991.

3. Merida I, Avila-Flores A, Merino E. Diacylglycerol kinases: at the hub of cell signalling. Biochem J. 2008;409(1):1-18.

4. Merida I, Andrada E, Gharbi SI, Avila-Flores A. Redundant and specialized roles for diacylglycerol kinases alpha and zeta in the control of T cell functions. Sci Signal.

2015;8(374):re6.

5. Zhong XP, Hainey EA, Olenchock BA, et al. Enhanced T cell responses due to diacylglycerol kinase zeta deficiency. Nat Immunol. 2003;4(9):882-890.

6. Andrada E, Liebana R, Merida I. Diacylglycerol Kinase zeta Limits Cytokine-dependent Expansion of CD8+ T Cells with Broad Antitumor Capacity. EBioMedicine. 2017;19:39-48.

7. Jing W, Gershan JA, Holzhauer S, et al. T Cells Deficient in Diacylglycerol Kinase zeta Are Resistant to PD-1 Inhibition and Help Create Persistent Host Immunity to Leukemia. Cancer Res. 2017;77(20):5676-5686.

8. Wesley EM, Xin G, McAllister D, et al. Diacylglycerol kinase zeta (DGKzeta) and Casitas b-lineage proto-oncogene b-deficient mice have similar functional outcomes in $\mathrm{T}$ cells but DGKzeta-deficient mice have increased $\mathrm{T}$ cell activation and tumor clearance.

Immunohorizons. 2018;2(4):107-118.

9. Schmidt AM, Zou T, Joshi RP, et al. Diacylglycerol kinase zeta limits the generation of natural regulatory T cells. Sci Signal. 2013;6(303):ra101.

10. Shin J, Xie D, Zhong XP. MicroRNA-34a enhances T cell activation by targeting diacylglycerol kinase zeta. PLoS One. 2013;8(10):e77983.

11. Zheng Y, Zha Y, Driessens G, Locke F, Gajewski TF. Transcriptional regulator early growth response gene 2 (Egr2) is required for T cell anergy in vitro and in vivo. $J$ Exp Med. 2012;209(12):2157-2163.

12. Sun YX, Li H, Feng Q, et al. Dysregulated miR34a/diacylglycerol kinase zeta interaction enhances T-cell activation in acquired aplastic anemia. Oncotarget. 2017;8(4):6142-6154.

13. Chongsathidkiet P, Jackson C, Koyama S, et al. Sequestration of T cells in bone marrow in the setting of glioblastoma and other intracranial tumors. Nature Medicine.

2018;24(9):1459-1468.

14. Arieta Kuksin C, Gonzalez-Perez G, Minter LM. CXCR4 expression on pathogenic T cells facilitates their bone marrow infiltration in a mouse model of aplastic anemia. Blood. 2015;125(13):2087-2094.

15. Macintyre AN, Finlay D, Preston G, et al. Protein kinase B controls transcriptional programs that direct cytotoxic $\mathrm{T}$ cell fate but is dispensable for $\mathrm{T}$ cell metabolism. Immunity. 2011;34(2):224-236.

16. Janas ML, Groves P, Kienzle N, Kelso A. IL-2 Regulates Perforin and Granzyme Gene Expression in CD8+ T Cells Independently of Its Effects on Survival and Proliferation. The Journal of Immunology. 2005;175(12):8003-8010.

17. Fontenot JD, Gavin MA, Rudensky AY. Foxp3 programs the development and function of CD4+CD25+ regulatory T cells. Nat Immunol. 2003;4(4):330-336.

18. Nakagawa MM, Rathinam CV. Constitutive Activation of the Canonical NF-\&\#x3ba;B

Pathway Leads to Bone Marrow Failure and Induction of Erythroid Signature in

Hematopoietic Stem Cells. Cell Reports. 2018;25(8):2094-2109.e2094.

19. Andrada E, Liebana R, Merida I. Diacylglycerol Kinase zeta Limits Cytokine-dependent Expansion of CD8(+) T Cells with Broad Antitumor Capacity. EBioMedicine. 2017;19:39-48. 
20. Sancho D, Gomez M, Sanchez-Madrid F. CD69 is an immunoregulatory molecule induced following activation. Trends Immunol. 2005;26(3):136-140.

21. Sloand E, Kim S, Maciejewski JP, Tisdale J, Follmann D, Young NS. Intracellular interferon-gamma in circulating and marrow $\mathrm{T}$ cells detected by flow cytometry and the response to immunosuppressive therapy in patients with aplastic anemia. Blood.

2002;100(4):1185-1191.

22. Singh BK, Lu W, Schmidt Paustian AM, et al. Diacylglycerol kinase zeta promotes allergic airway inflammation and airway hyperresponsiveness through distinct mechanisms. Sci Signal. 2019;12(597).

23. Zoumbos NC, Gascon P, Djeu JY, Young NS. Interferon is a mediator of hematopoietic suppression in aplastic anemia in vitro and possibly in vivo. Proc Natl Acad Sci U S A. 1985;82(1):188-192.

24. Hosokawa K, Muranski P, Feng X, et al. Identification of novel microRNA signatures linked to acquired aplastic anemia. Haematologica. 2015;100(12):1534-1545.

25. Clucas DB, Fox LC, Wood EM, et al. Revisiting acquired aplastic anaemia: current concepts in diagnosis and management. Intern Med J. 2019;49(2):152-159.

26. Chen K, Liu J, Heck S, Chasis JA, An X, Mohandas N. Resolving the distinct stages in erythroid differentiation based on dynamic changes in membrane protein expression during erythropoiesis. Proc Natl Acad Sci U S A. 2009;106(41):17413-17418.

27. Luzzatto L, Risitano AM. Advances in understanding the pathogenesis of acquired aplastic anaemia. Br J Haematol. 2018;182(6):758-776.

28. Kondo M, Wagers AJ, Manz MG, et al. Biology of hematopoietic stem cells and progenitors: implications for clinical application. Annu Rev Immunol. 2003;21:759-806. 29. Siatecka M, Bieker JJ. The multifunctional role of EKLF/KLF1 during erythropoiesis. Blood. 2011;118(8):2044-2054.

30. Qian H, Buza-Vidas N, Hyland CD, et al. Critical role of thrombopoietin in maintaining adult quiescent hematopoietic stem cells. Cell Stem Cell. 2007;1(6):671-684.

31. Yoshihara H, Arai F, Hosokawa K, et al. Thrombopoietin/MPL signaling regulates hematopoietic stem cell quiescence and interaction with the osteoblastic niche. Cell Stem Cell. 2007;1(6):685-697.

32. Rose S, Misharin A, Perlman H. A novel Ly6C/Ly6G-based strategy to analyze the mouse splenic myeloid compartment. Cytometry A. 2012;81(4):343-350.

33. Liyanage SE, Gardner PJ, Ribeiro J, et al. Flow cytometric analysis of inflammatory and resident myeloid populations in mouse ocular inflammatory models. Exp Eye Res.

2016;151:160-170.

34. Sawai CM, Babovic S, Upadhaya S, et al. Hematopoietic Stem Cells Are the Major Source of Multilineage Hematopoiesis in Adult Animals. Immunity. 2016;45(3):597-609.

35. Maeda Y, Seki N, Sato N, Sugahara K, Chiba K. Sphingosine 1-phosphate receptor type 1 regulates egress of mature T cells from mouse bone marrow. Int Immunol. 2010;22(6):515525 .

36. Kina T, Ikuta K, Takayama E, et al. The monoclonal antibody TER-119 recognizes a molecule associated with glycophorin A and specifically marks the late stages of murine erythroid lineage. Br J Haematol. 2000;109(2):280-287.

37. Delbridge AR, Aubrey BJ, Hyland C, et al. The BH3-only proteins BIM and PUMA are not critical for the reticulocyte apoptosis caused by loss of the pro-survival protein BCL-XL. Cell Death Dis. 2017;8(7):e2914.

38. Thome JJ, Yudanin N, Ohmura Y, et al. Spatial map of human T cell

compartmentalization and maintenance over decades of life. Cell. 2014;159(4):814-828. 
39. Hosokawa K, Muranski P, Feng X, et al. Memory Stem T Cells in Autoimmune Disease: High Frequency of Circulating CD8+ Memory Stem Cells in Acquired Aplastic Anemia. $J$ Immunol. 2016;196(4):1568-1578.

40. Hu X, Gu Y, Wang Y, Cong Y, Qu X, Xu C. Increased CD4+ and CD8+ effector memory T cells in patients with aplastic anemia. Haematologica. 2009;94(3):428-429.

41. Bloom ML, Wolk AG, Simon-Stoos KL, Bard JS, Chen J, Young NS. A mouse model of lymphocyte infusion-induced bone marrow failure. Exp Hematol. 2004;32(12):1163-1172.

42. Garside P, Reid S, Steel M, Mowat AM. Differential cytokine production associated with distinct phases of murine graft-versus-host reaction. Immunology. 1994;82(2):211-214.

43. Chen X, Das R, Komorowski R, et al. Blockade of interleukin-6 signaling augments regulatory T-cell reconstitution and attenuates the severity of graft-versus-host disease. Blood. 2009;114(4):891-900.

44. Avila-Flores A, Arranz-Nicolas J, Andrada E, Soutar D, Merida I. Predominant contribution of DGKzeta over DGKalpha in the control of PKC/PDK-1-regulated functions in T cells. Immunol Cell Biol. 2017;95(6):549-563.

45. Riese MJ, Moon EK, Johnson BD, Albelda SM. Diacylglycerol Kinases (DGKs): Novel Targets for Improving T Cell Activity in Cancer. Front Cell Dev Biol. 2016;4:108.

46. Yang E, Singh BK, Paustian AM, Kambayashi T. Diacylglycerol Kinase zeta Is a Target To Enhance NK Cell Function. J Immunol. 2016;197(3):934-941.

47. Shinoda K, Tokoyoda K, Hanazawa A, et al. Type II membrane protein CD69 regulates the formation of resting T-helper memory. Proc Natl Acad Sci U S A. 2012;109(19):74097414.

48. Di Rosa F, Pabst R. The bone marrow: a nest for migratory memory T cells. Trends Immunol. 2005;26(7):360-366.

49. Young NS. Current concepts in the pathophysiology and treatment of aplastic anemia. Hematology Am Soc Hematol Educ Program. 2013;2013:76-81.

50. Fischer U, Ruckert C, Hubner B, et al. CD34+ gene expression profiling of individual children with very severe aplastic anemia indicates a pathogenic role of integrin receptors and the proapoptotic death ligand TRAIL. Haematologica. 2012;97(9):1304-1311.

51. Lin FC, Karwan M, Saleh B, et al. IFN-gamma causes aplastic anemia by altering hematopoietic stem/progenitor cell composition and disrupting lineage differentiation. Blood. 2014;124(25):3699-3708.

52. Tie R, Li H, Cai S, et al. Interleukin-6 signaling regulates hematopoietic stem cell emergence. Exp Mol Med. 2019;51(10):124.

53. Sun W, Wu Z, Lin Z, et al. Macrophage TNF-alpha licenses donor T cells in murine bone marrow failure and can be implicated in human aplastic anemia. Blood. 2018;132(26):27302743.

54. Moroi AJ, Zwifelhofer NM, Riese MJ, Newman DK, Newman PJ. Diacylglycerol kinase zeta is a negative regulator of GPVI-mediated platelet activation. Blood Adv. 2019;3(7):11541166.

55. Comito RR, Badu LA, Forcello N. Nivolumab-induced aplastic anemia: A case report and literature review. J Oncol Pharm Pract. 2019;25(1):221-225.

56. Filetti M, Giusti R, Di Napoli A, Iacono D, Marchetti P. Unexpected serious aplastic anemia from PD-1 inhibitors: beyond what we know. Tumori. 2019;105(6):NP48-NP51. 57. Rouvinov K, Nalbandyan K, Kozlov V, Peled N, Yakobson A. Nivolumab Induced Lethal Aplastic Anemia in a Patient with Metastatic Melanoma. Case Rep Oncol. 2019;12(1):29-32. 


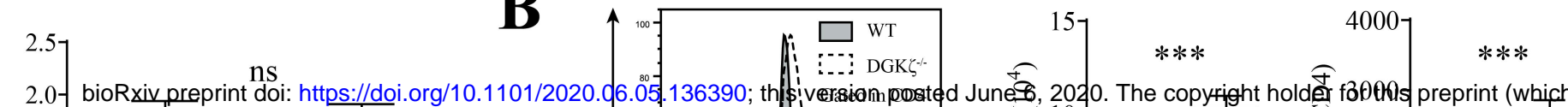
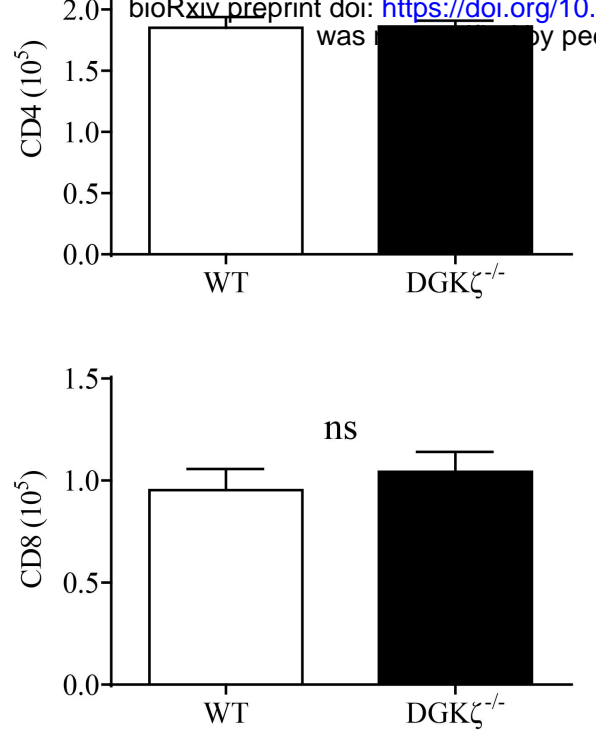
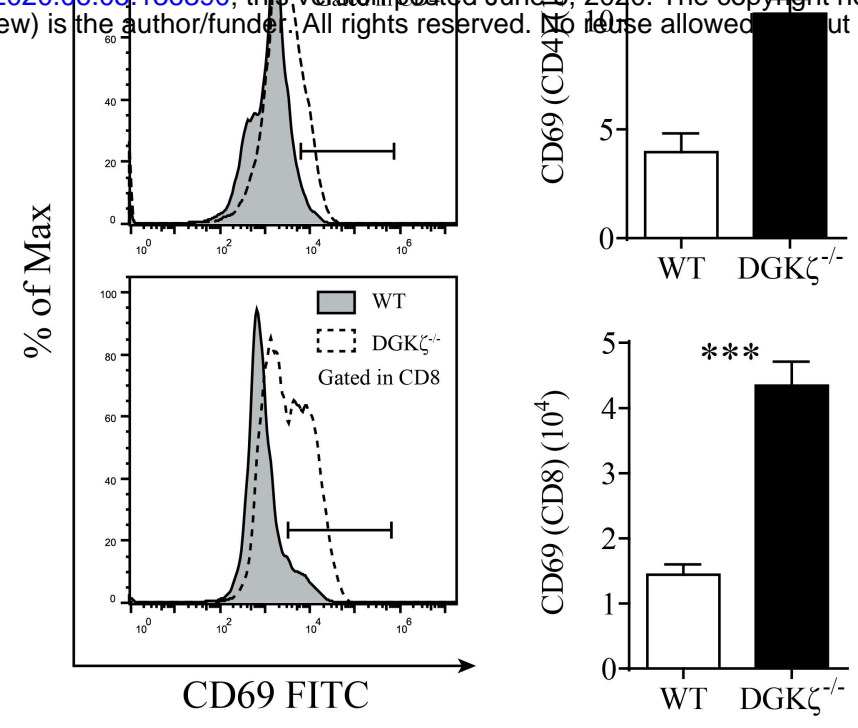

C
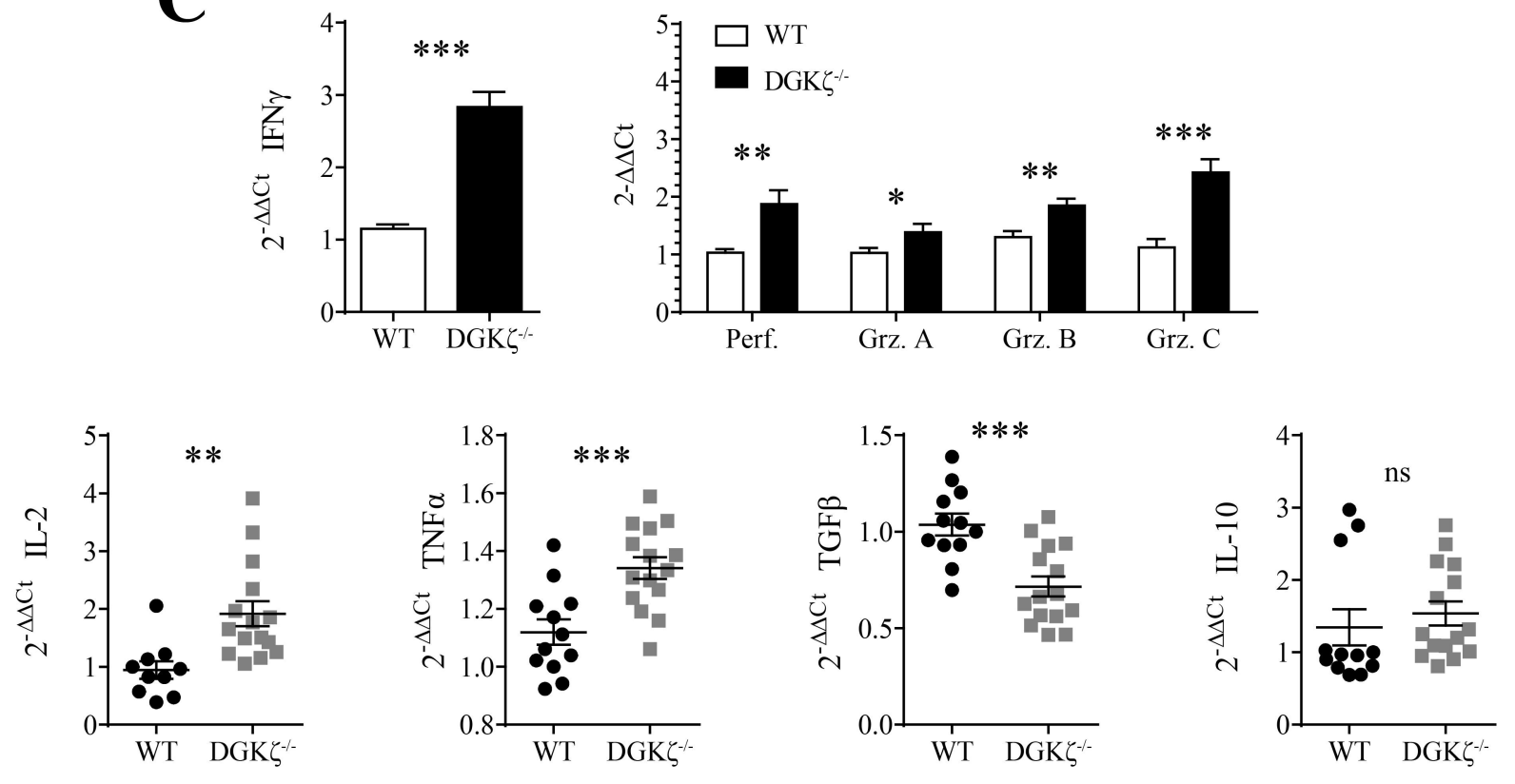

D
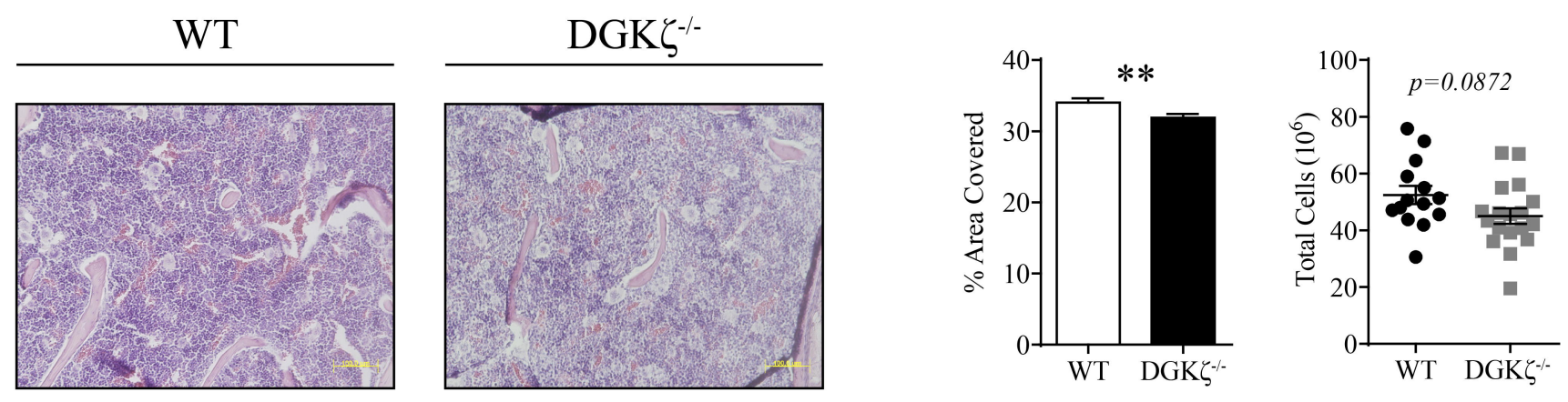

$\mathbf{E}$
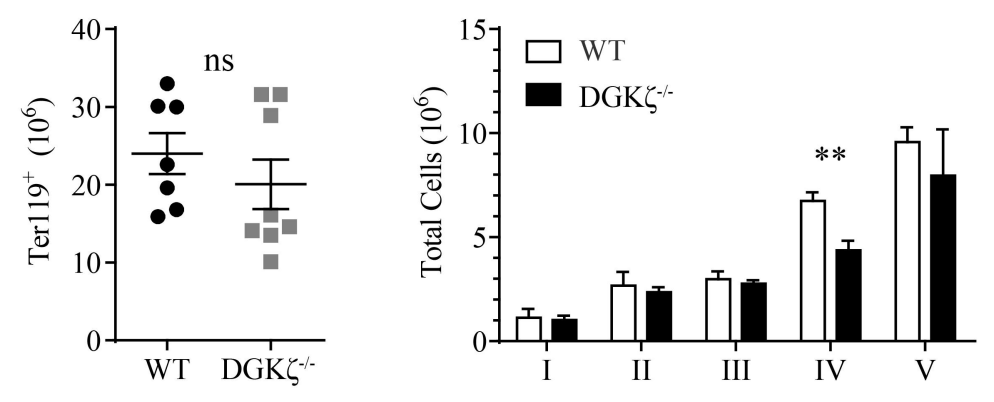

Figure 1 


\section{A
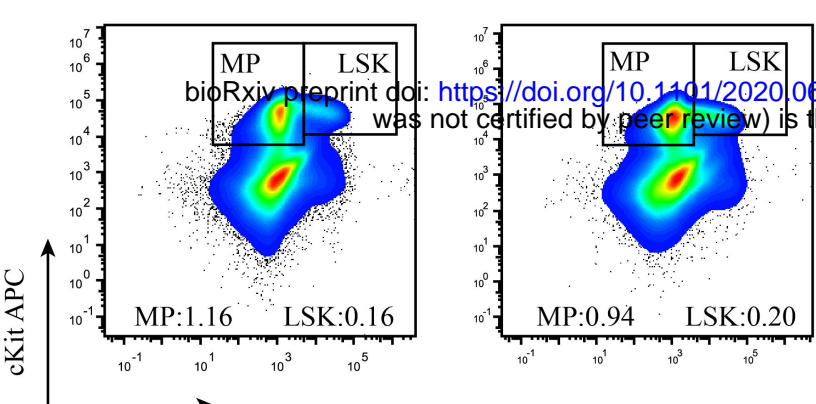

1.5

10

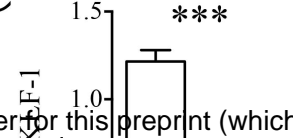

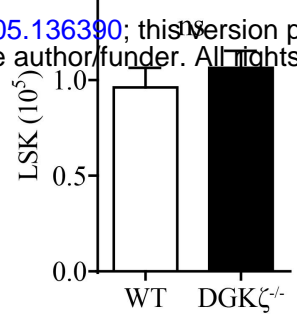

mission.
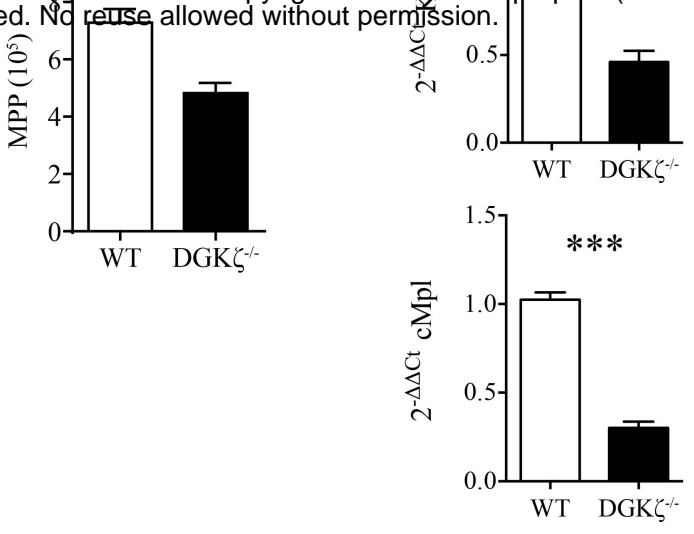

B
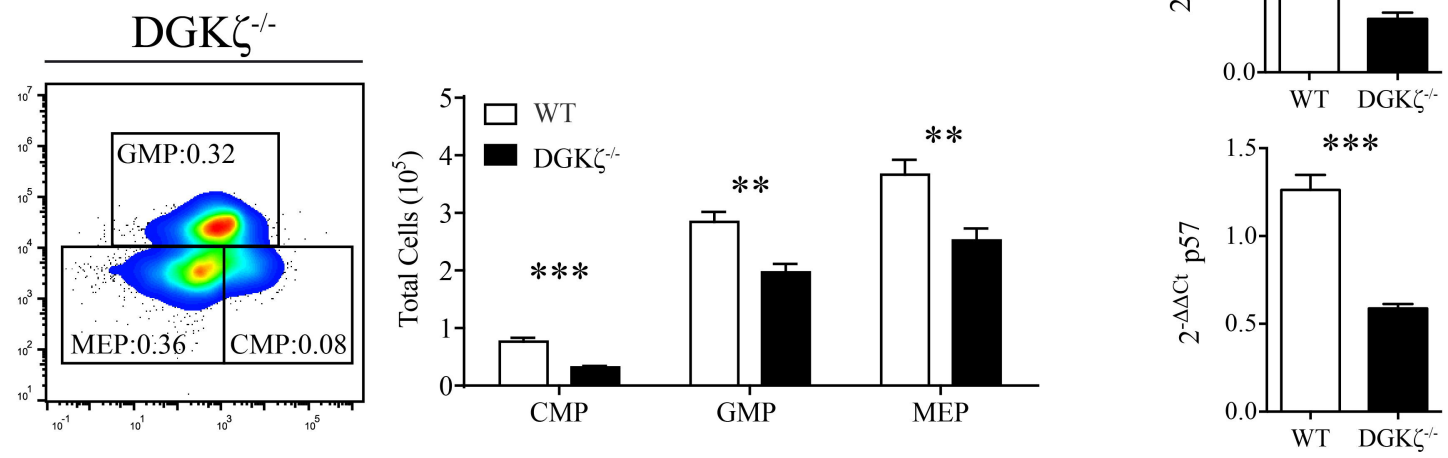

CD34 PE

D
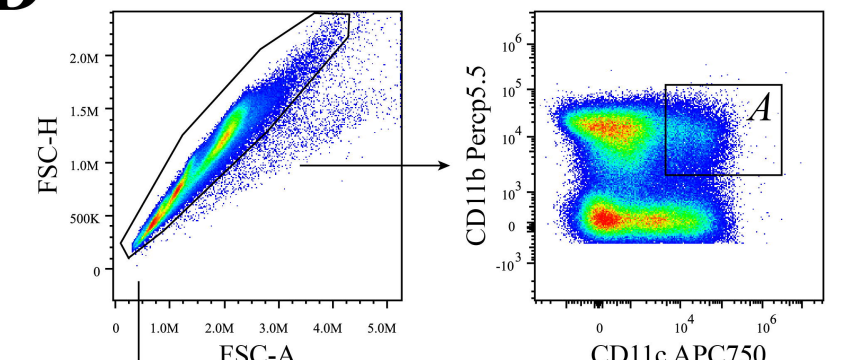

A: Dendritic Cells

B: Natural Killer cells (NKs)

C:Neutrophils

$D$ : Macrophages $(M \varphi)$ and Monocytes

E: Eosinophils

F: InflammatoryMacrophages
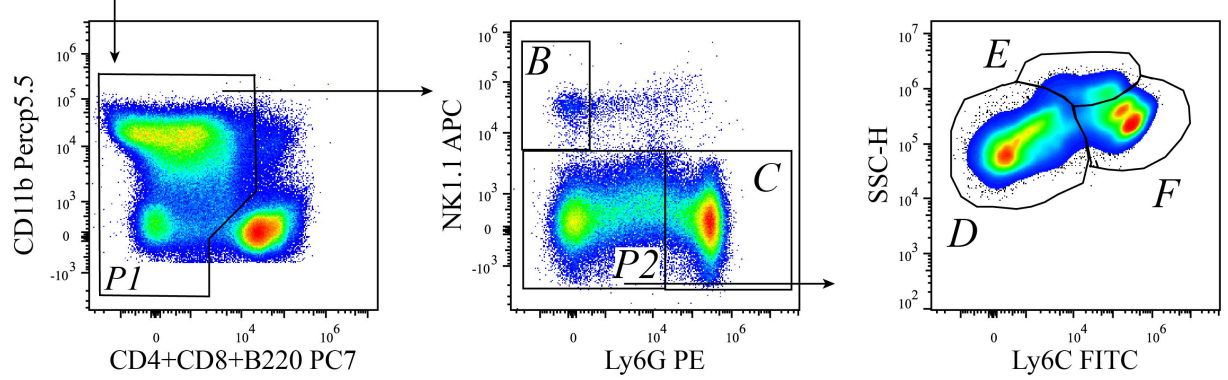

E
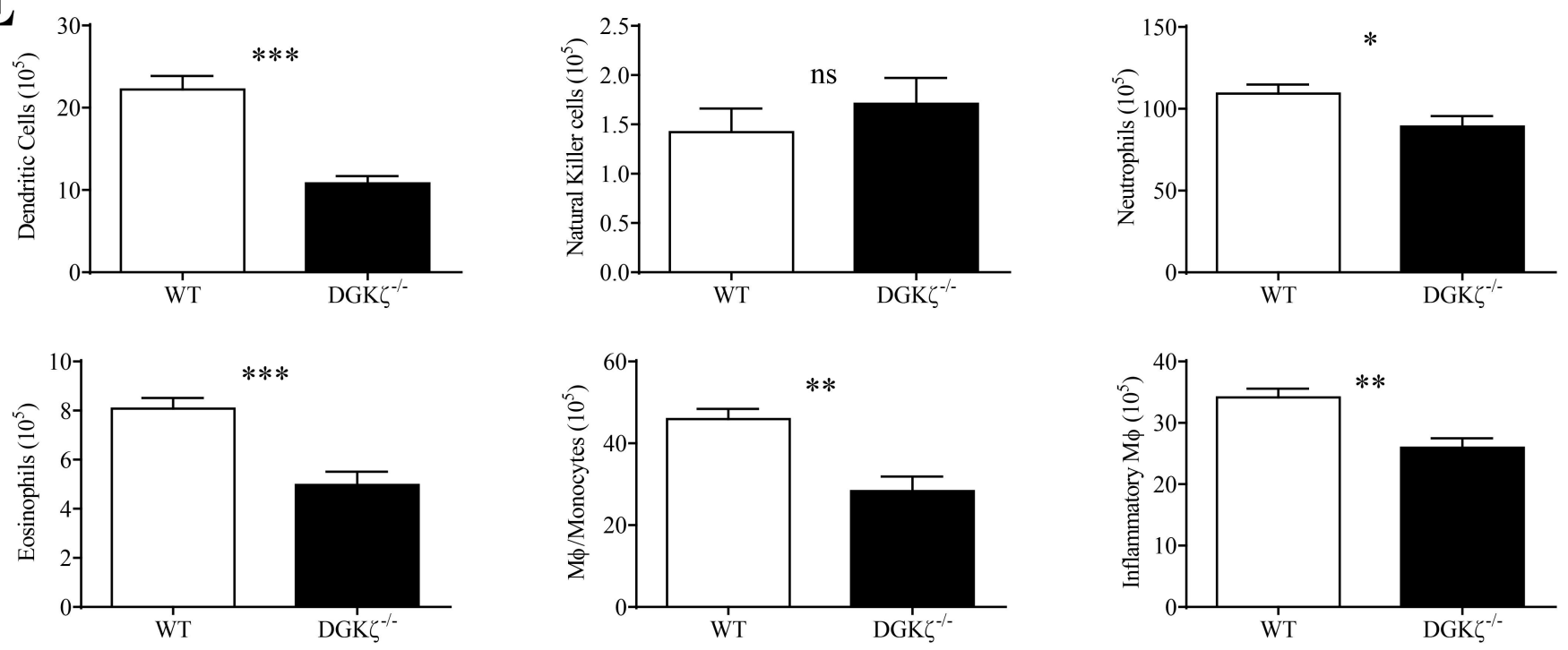

Figure 2 
$n$
$n$
0
0
0
0
0
0
0

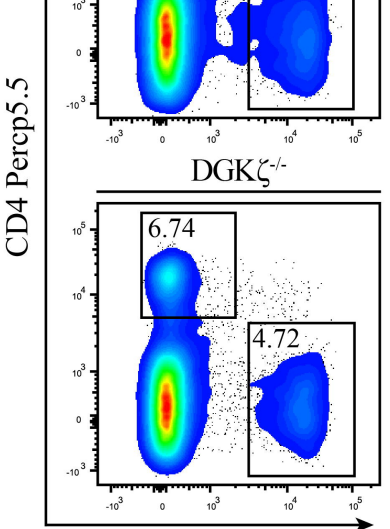

CD8 EF450

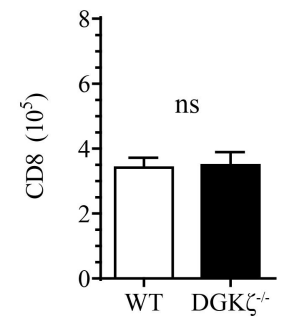

C

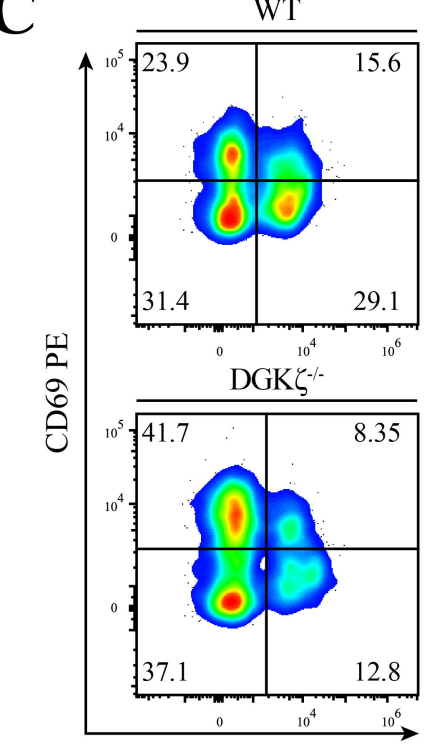

S1P1 APC
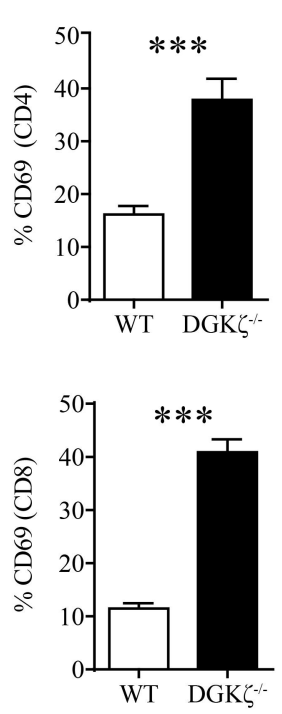
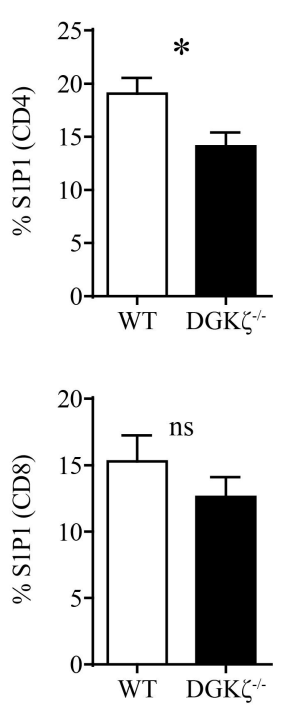

$\left.{ }^{600}\right] * * *$

for for this pre

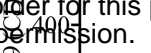
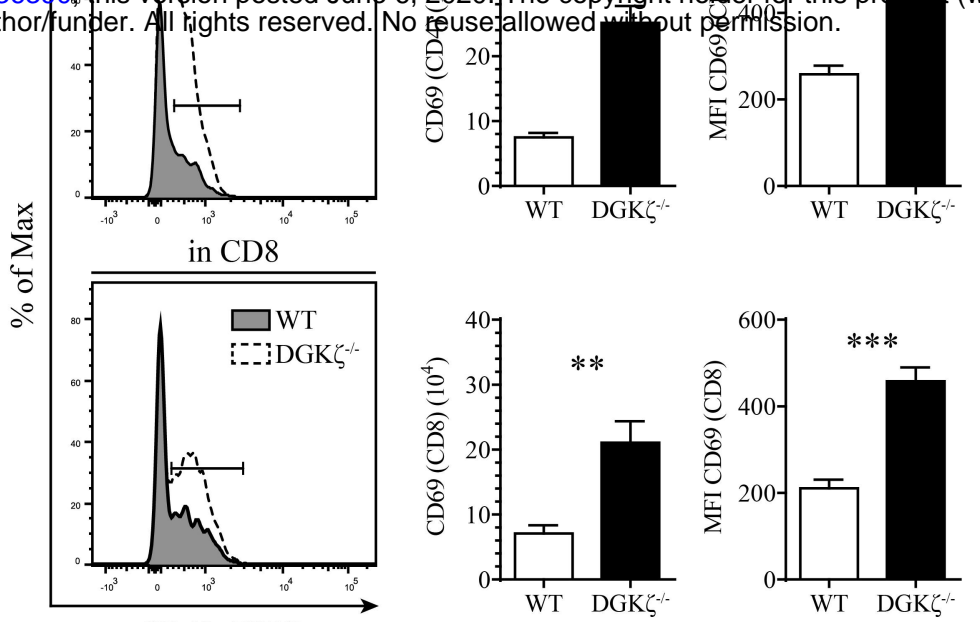

WT DGK $^{-/}$
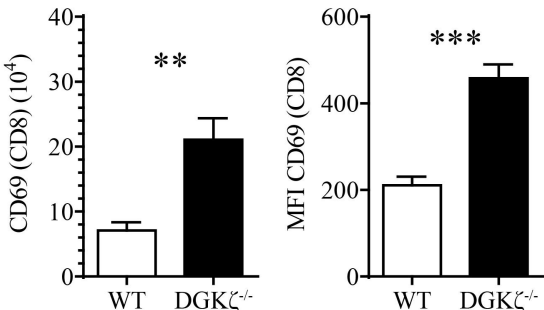

CD69 FITC

D
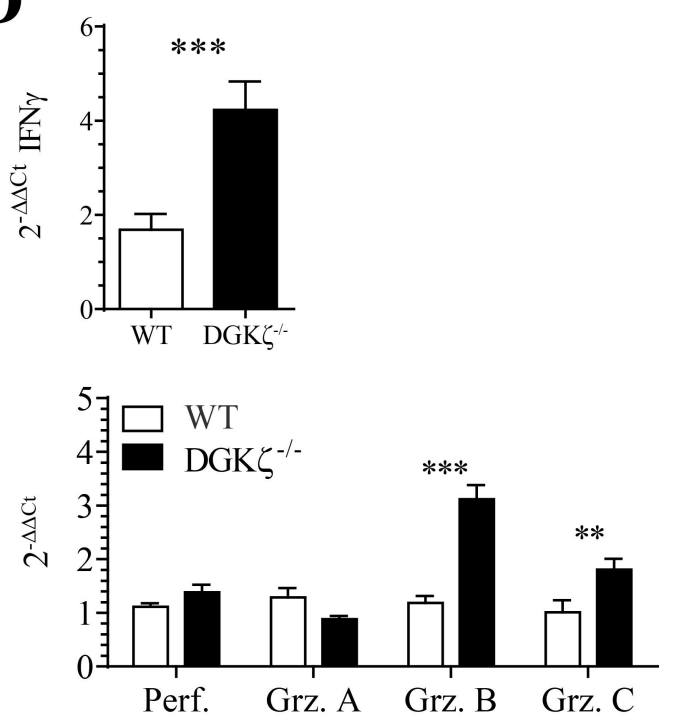

$\mathbf{E}$
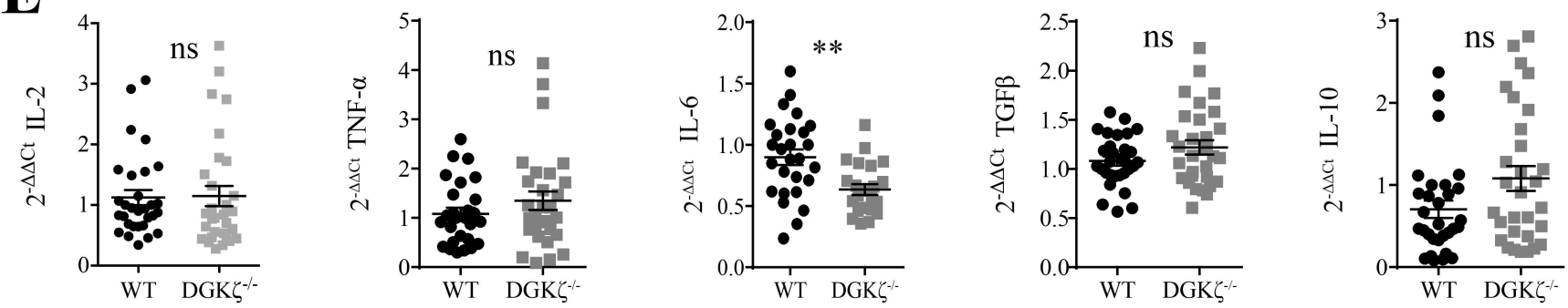

F
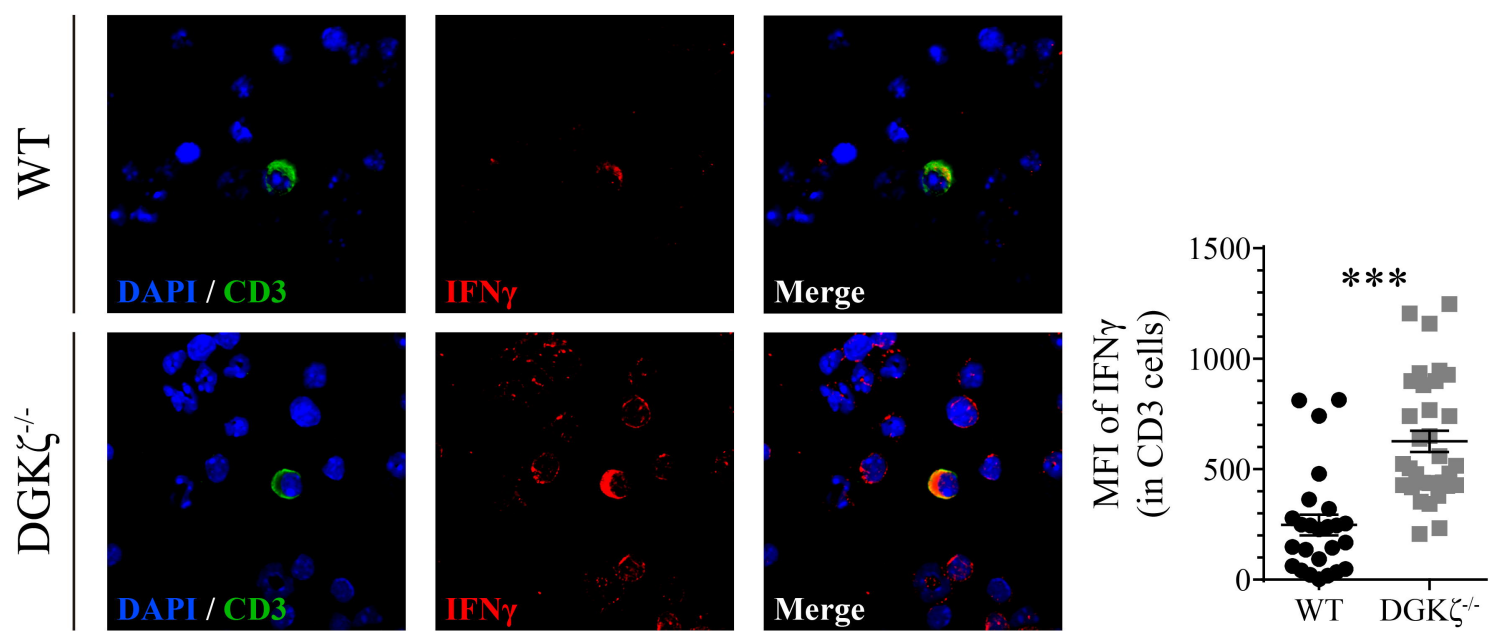

Figure 3 

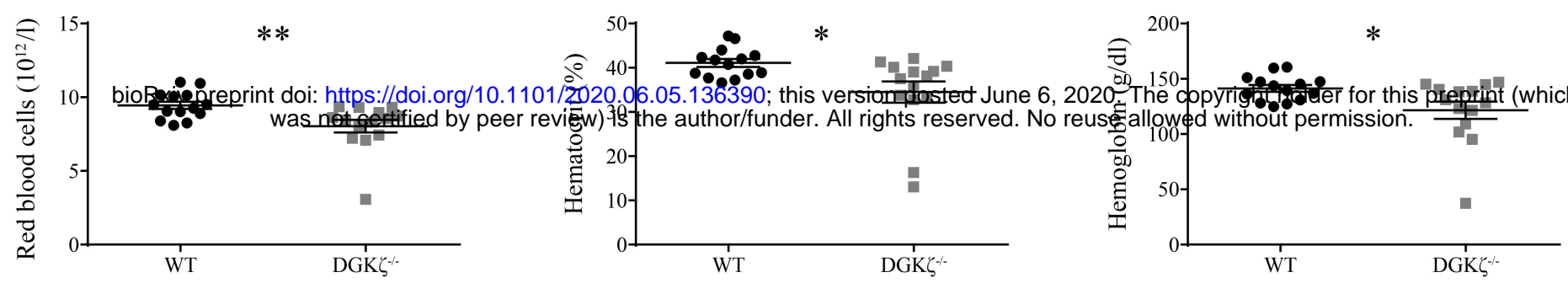

B

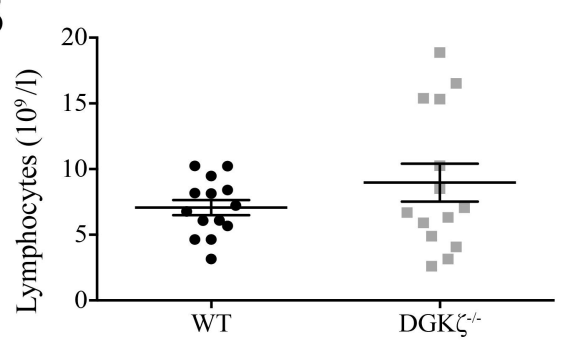

C

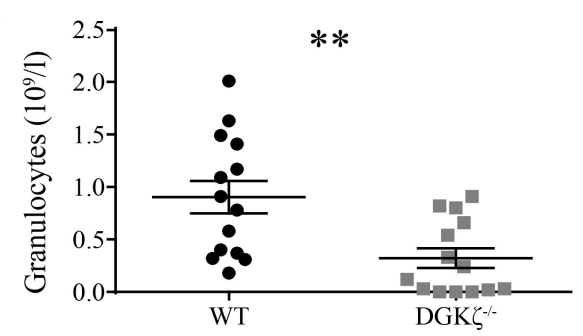

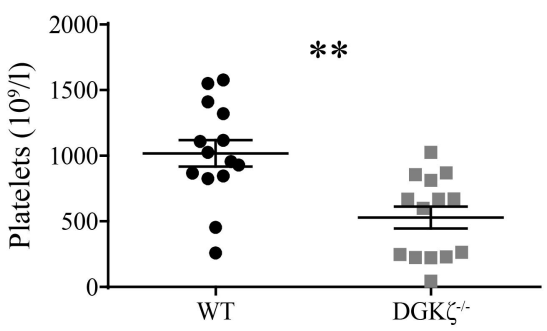

D
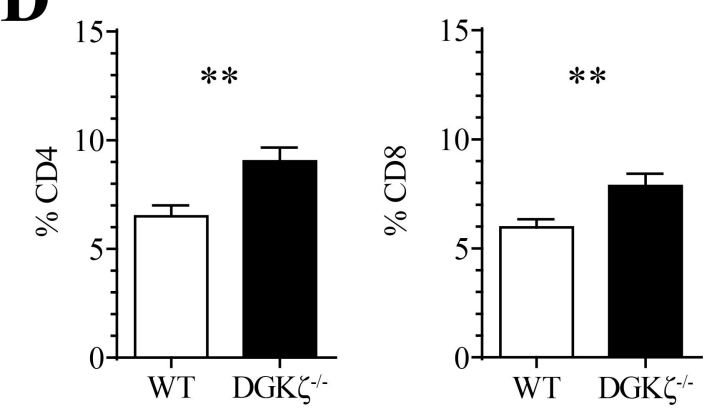

E
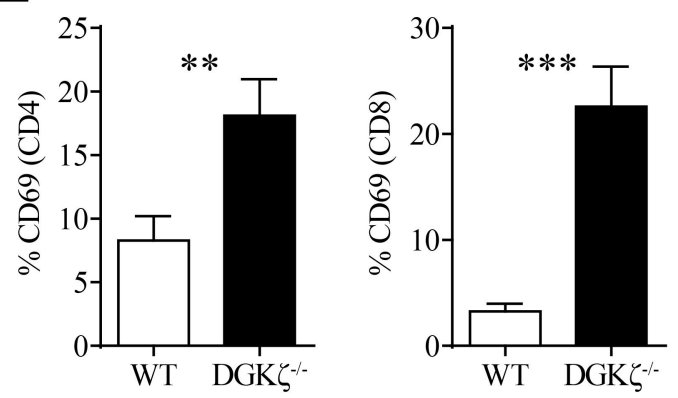

F

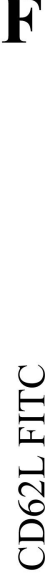

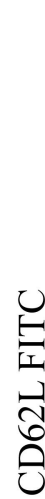

WT

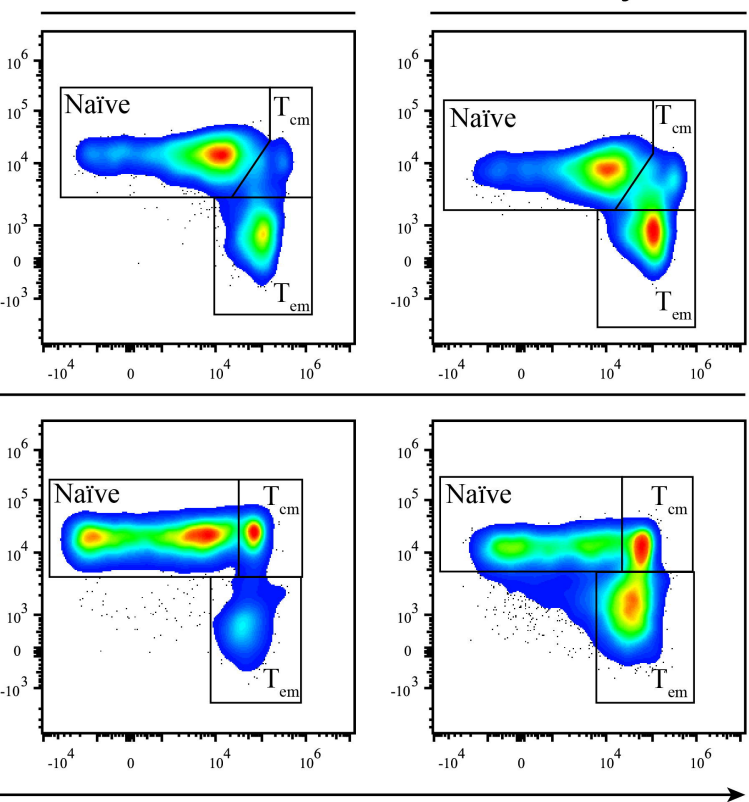

CD44 APC

CD4

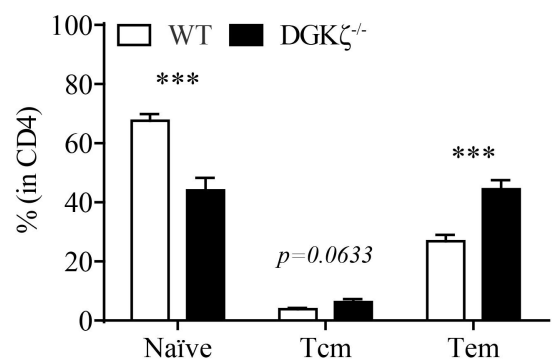

CD8

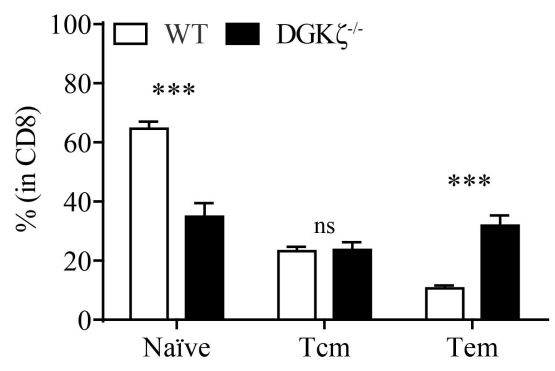

G Spleen
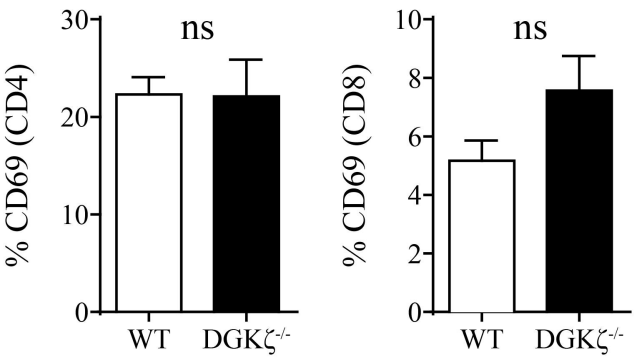
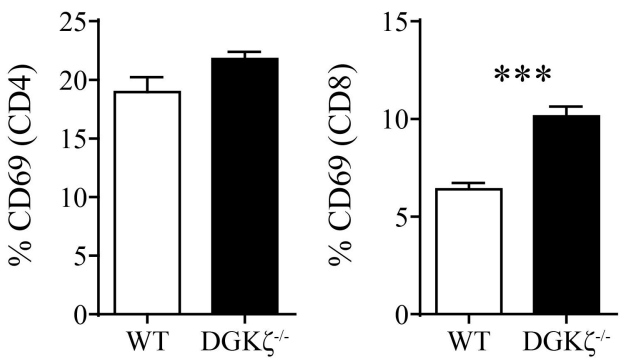

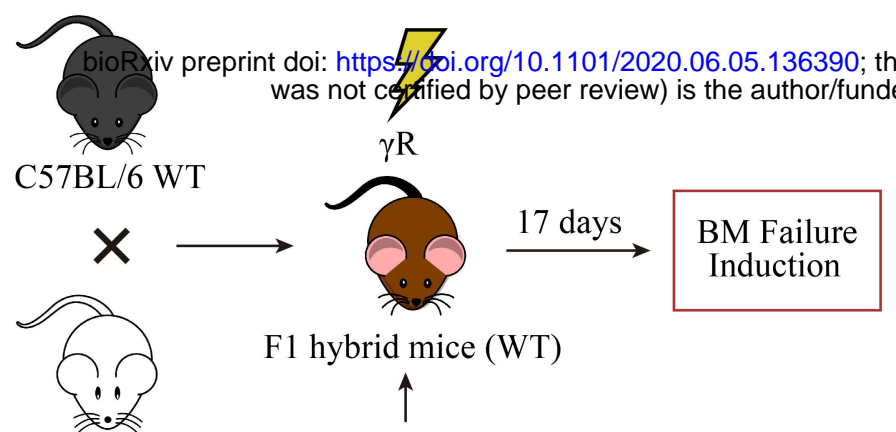

F1 hybrid mice (WT)

BALB/c WT

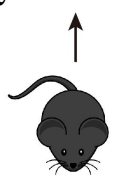

ns

Splenocytes from

WT or DGK $\zeta^{-/ C}$ C57BL $/ 6$

C

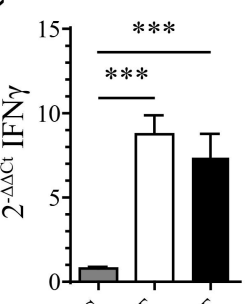

बुं से सर

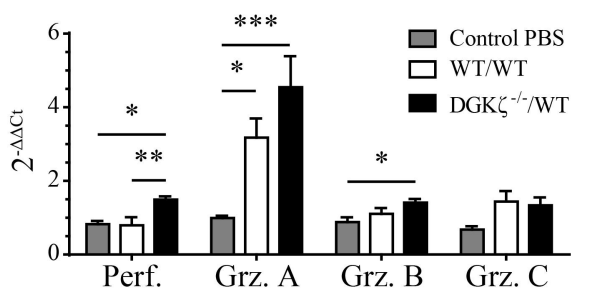

Perf.
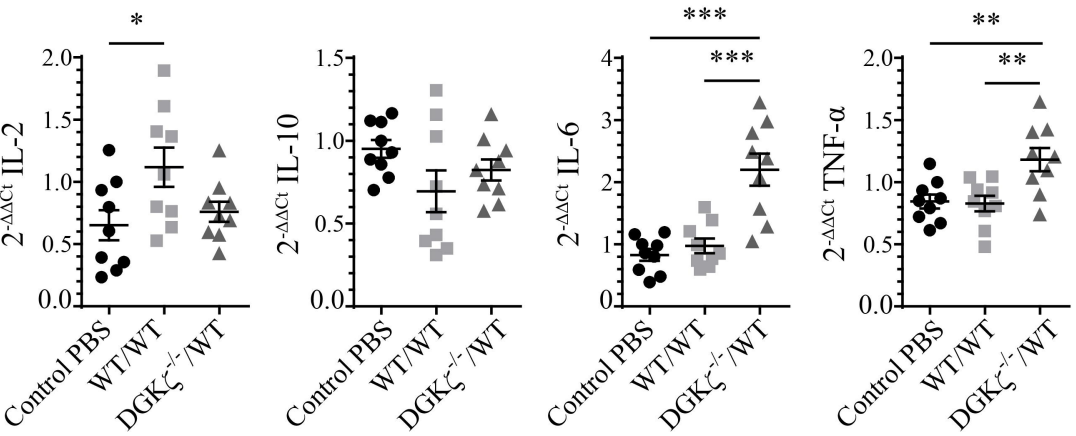

D

Control PBS

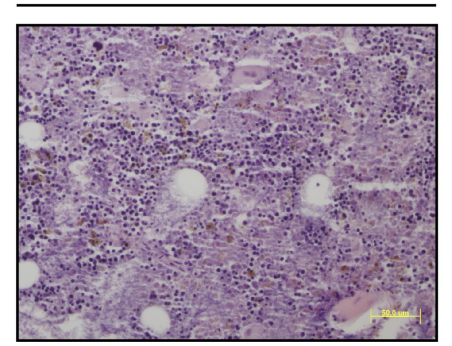

WT/WT

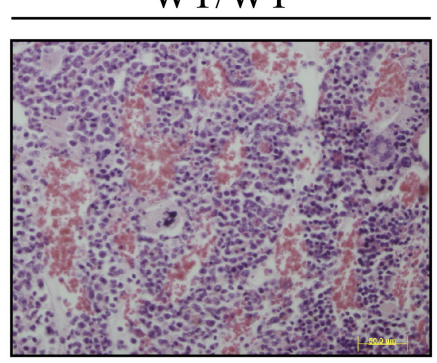

DGK $\zeta^{-/ /} / \mathrm{WT}$

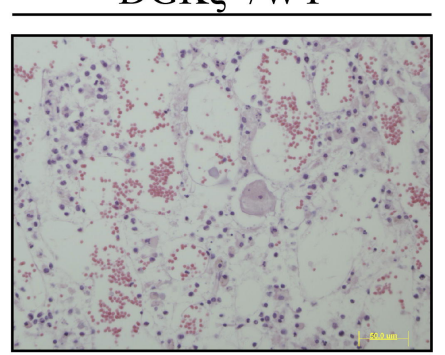

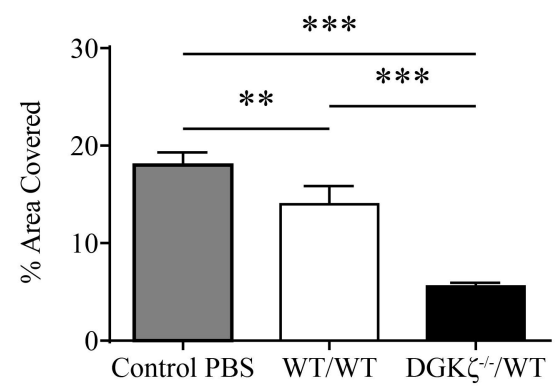

